\title{
Barium-isotopic fractionation in seawater mediated by barite cycling and oceanic circulation
}

\author{
Tristan J. Horner ${ }^{\mathrm{a}, *}$, Christopher W. Kinsley ${ }^{\mathrm{b}}$, and Sune G. Nielsen ${ }^{\mathrm{c}}$
}

July 9, 2015

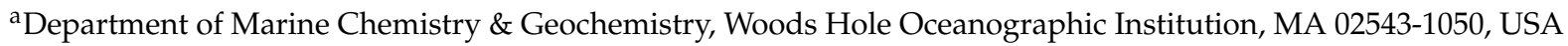

${ }^{b}$ Department of Earth, Atmospheric and Planetary Sciences, Massachusetts Institute of Technology, Cambridge MA 02139-4307, USA

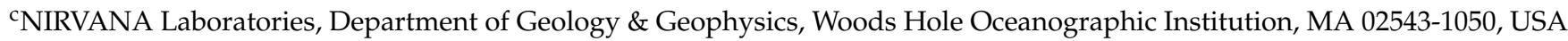

${ }^{*}$ Corresponding author: Tristan.Horner@whoi.edu

\section{Highlights}

- First full seawater depth profile of co-located [Ba]- $\delta^{138 / 134} \mathrm{Ba}_{\mathrm{NIST}}$

- Origin of Ba-isotopic variations are best explained by barite cycling

- Regional circulation strongly influences depth structure of $\delta^{138 / 134} \mathrm{Ba}_{\mathrm{NIST}}$

- Data establish a baseline of Ba-isotopic variability in the marine realm

Keywords: barium; isotopic fractionation; barite; seawater; biogeochemistry 


\begin{abstract}
The marine biogeochemical cycle of $\mathrm{Ba}$ is thought to be controlled by particulate $\mathrm{BaSO}_{4}$ (barite) precipitation associated with the microbial oxidation of organic carbon and its subsequent dissolution in the $\mathrm{BaSO}_{4}$-undersaturated water column. Despite many of these processes being largely unique to Ba cycling, concentrations of $\mathrm{Ba}$ and $\mathrm{Si}$ in seawater exhibit a strong linear correlation. The reasons for this correlation are ambiguous, as are the depth ranges corresponding to the most active $\mathrm{BaSO}_{4}$ cycling and the intermediate sources of $\mathrm{Ba}$ to particulate $\mathrm{BaSO}_{4}$. Stable isotopic analyses of dissolved $\mathrm{Ba}$ in seawater should help address these issues, as Ba-isotopic compositions are predicted to be sensitive to the physical and biogeochemical process that cycle Ba. We report a new methodology for the determination of dissolved Ba-isotopic compositions in seawater and results from a 4,500 m depth profile in the South Atlantic at $39.99^{\circ} \mathrm{S}, 0.92^{\circ} \mathrm{E}$ that exhibit oceanographically-consistent variation with depth. These data reveal that water masses obtain their $[\mathrm{Ba}]$ and $\mathrm{Ba}$-isotopic signatures when at or near the surface, which relates to the cycling of marine $\mathrm{BaSO}_{4}$. The shallow origin of these signatures requires that the substantial Ba-isotopic variations in the bathypelagic zone were inherited from when those deep waters were last ventilated. Indeed, the water column below $600 \mathrm{~m}$ is well explained by conservative mixing of water masses with distinct [Ba] and Ba-isotopic compositions. This leads us to conclude that large scale oceanic circulation is important for sustaining the similar oceanographic distributions of $\mathrm{Ba}$ and $\mathrm{Si}$ in the South Atlantic, and possibly elsewhere. These data demonstrate that the processes of organic carbon oxidation, $\mathrm{BaSO}_{4}$ cycling, and Ba-isotopic fractionation in seawater are closely coupled, such that Ba-isotopic analyses harbor great potential as a tracer of the carbon cycle in the modern and paleo-oceans.
\end{abstract}




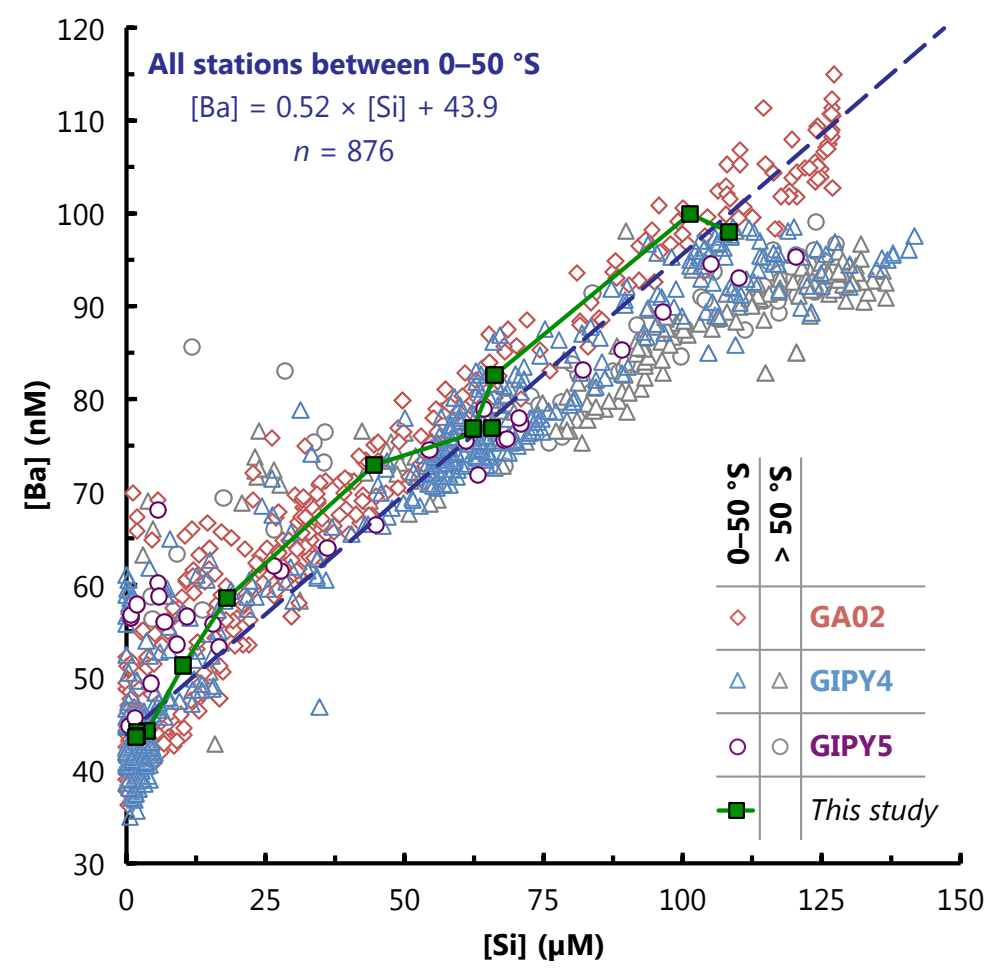

Figure 1: Co-variation of dissolved [Ba] and [Si] in the South Atlantic. Data sources are this study (solid line links profile data) and The GEOTRACES Intermediate Data Product 2014 (Mawji et al., 2015), the latter of which encompasses three separate cruises in the South Atlantic and Southern Oceans (Atlantic Sector) spanning from the Equator to $\approx 70{ }^{\circ} \mathrm{S}$ : GA02 (JC057; diamonds, data courtesy of A. Vilela and J.M. Godoy), GIPY4 (MD166; triangles, data courtesy of F. Dehairs and available from Speich et al. 2008; methods describing how the data were obtained and their interpretation are discussed in Hoppema et al. 2010), and GIPY5 (ANTXXIV/3; circles, data courtesy of T. Roeske and M. Rutgers v. d. Loeff and are available from Roeske and Rutgers v. d. Loeff 2012; methods describing how the data were obtained are available in Roeske et al. 2012a,b). The best-fit York regression (dashed line) of the 876 GEOTRACES co-located [Ba]-[Si] observations from $<50{ }^{\circ} \mathrm{S}$ (filled symbols) yields $[\mathrm{Ba}]=0.52( \pm 0.01) \times[\mathrm{Si}]+43.9( \pm 0.2)$; regression uncertainties correspond to $\pm 2 \mathrm{SD}$. Individual measurements of $[\mathrm{Ba}]$ and [Si] were assigned relative uncertainties of $\pm 5 \%$, except when [Si] was between $1-10 \mu \mathrm{M}( \pm 10 \%)$ and $<1 \mu \mathrm{M}( \pm 25 \%)$. Profile data from $>50^{\circ} \mathrm{S}$ (open symbols) are not regressed in the South Atlantic trend, as data from high latitudes possess significantly gentler slopes and larger intercepts (see e.g. Hoppema et al., 2010).

\section{Introduction}

The marine chemistry of Ba (barium) has intrigued geochemists for decades owing to its nutrient-like dissolved profile in seawater (e.g. Chow and Goldberg, 1960), despite lacking a definitive physiological use in phytoplankton. Distributions of dissolved Ba are strongly linearly correlated with those of Si (silicon) throughout much of the global ocean (Fig. 1). Unlike Si however, Ba is rarely quantitatively removed from surface seawater and is around 1,000 times less abundant (Wolgemuth and Broecker, 1970; Chan et al., 1977). The near-surface seawater drawdown of $\mathrm{Ba}$ has generally been assumed to relate to the precipitation of $\mathrm{BaSO}_{4}$ (barite; e.g. Dehairs et al., 1980), even though the vast majority of the world's oceans are undersaturated with respect to this mineral phase (e.g. Monnin et al., 1999). This apparent contradiction is most commonly explained by invoking the existence of ephemeral $\mathrm{BaSO}_{4}$-supersaturated 'microenvironments' in the water column that favor precipitation of discrete $\mu \mathrm{m}$-sized $\mathrm{BaSO}_{4}$ crystals (e.g. Dehairs et al., 1980; Bishop, 1988). The loci of maximum pelagic $\mathrm{BaSO}_{4}$ - and heterotrophic bacterial production are spatially correlated (e.g. Dehairs et al., 2008), suggesting that the development of $\mathrm{BaSO}_{4}$-forming microenvironments are associated with the microbial oxidation of sinking organic matter (e.g Chow and Goldberg, 1960). Regeneration of dissolved $\mathrm{Ba}$ at deeper depths likely relates to $\mathrm{BaSO}_{4}$ dissolution in under-saturated seawater, thus closing the open oceans internal Ba cycle and illustrating a remarkable set of linkages between the microbial loop, pelagic $\mathrm{BaSO}_{4}$ formation, and the cycling and export of $\mathrm{BaSO}_{4}$ and organic carbon.

Despite these substantial advances in our understanding of Ba biogeochemistry, several important questions persist regarding the modern Ba cycle. For example, the oceanographic processes that maintain the linear relationship 
between dissolved [Ba] and [Si] - but not between Ba and the other major algal nutrients nitrate and phosphate are poorly understood (Fig. 1; SI; Supplementary Information). Such a strong linear [Ba]-[Si] relationship is perhaps surprising, as $\mathrm{BaSO}_{4}$ precipitation and dissolution are not diatom-dependent (e.g. Ganeshram et al., 2003), unlike marine Si cycling. Explanations for the correlation between Ba and Si range from local-scale processes that assume that Ba- and Si-bearing carrier phases are remineralized at roughly similar rates during transit through the ocean interior (e.g. Broecker and Peng, 1982) to biogeochemical processes occurring in the surface of the high latitude Southern and Atlantic Oceans that are only communicated to lower latitudes through large-scale oceanic circulation (as suggested for $\mathrm{Si}$, e.g. Sarmiento et al., 2004). Though seawater is likely the ultimate source of Ba ions to marine $\mathrm{BaSO}_{4}$, its precipitation is microbially-mediated (e.g. Bertram and Cowen, 1997), such that intermediate Ba sources may be incorporated during $\mathrm{BaSO}_{4}$ formation. One likely intermediate $\mathrm{Ba}$ source to $\mathrm{BaSO}_{4}$ formation is organic matter, in addition to $\mathrm{Ba}$ sourced from dissolved $\mathrm{Ba}^{2+}$ in seawater; a continuum between these two end-member sources may also exist (see e.g. Paytan and Griffith, 2007). Finally, the depth ranges over which the most intensive $\mathrm{BaSO}_{4}$ precipitation occurs in the water column remain inadequately constrained. Estimates of this depth range vary from exclusively in the upper few hundred meters (e.g. Bishop, 1988) to continual formation with depth over several thousand meters (e.g. Van Beek et al., 2007). Answers to these questions are not only important for understanding the modern biogeochemical cycling of $\mathrm{Ba}$, but also for the application of $\mathrm{BaSO}_{4}$-based proxies in paleoceanography (e.g. Dymond et al., 1992; Falkner et al., 1994; Eagle et al., 2003; Griffith and Paytan, 2012; Ma et al., 2014).

Stable isotopic analyses of dissolved Ba in seawater would help address all three of these unresolved issues, as isotopic tracers are a powerful means to probe mineral-fluid reactions, establish mass balances, and study reaction conditions. A handful of recent studies have begun examining Ba-isotopic variability in nature, and have identified significant Ba-isotopic fractionation during mineral precipitation experiments (Von Allmen et al., 2010; Böttcher et al., 2012), between various $\mathrm{CaCO}_{3}$ minerals (Pretet, 2014), and most recently in igneous rocks (Miyazaki et al., 2014). Theoretical predictions support the direction, though not the magnitude, of Ba-isotopic fractionation observed during low-temperature mineral precipitation, which may be related to $\mathrm{Ba}^{2+}$ ion desolvation (Hofmann et al., 2012). However, examination of the Ba-isotopic systematics of seawater have hitherto escaped detailed study, largely because of the analytical difficulties associated with the isolation of sufficient quantities of chemically pure Ba from complex matrices such as seawater. Here, we address all of the aforementioned issues by presenting a $\approx 4,500 \mathrm{~m}$ depth profile of paired Ba-concentration and Ba-isotopic compositions from the South Atlantic Ocean. Our data reveal highly systematic patterns of Ba-isotopic fractionation in the open ocean that are oceanographically consistent with both the direction and magnitude of Ba-isotopic fractionation during $\mathrm{BaSO}_{4}$ cycling, modulated by basin-scale oceanic circulation.

\section{Samples, sampling, and methods}

\subsection{Hydrographic context}

Thirteen water samples were selected for Ba-isotopic analysis from a complete depth profile spanning $\approx 4,500 \mathrm{~m}$ at Station 6 of GA10E (D357; $39.99{ }^{\circ} \mathrm{S}, 0.92{ }^{\circ} \mathrm{E}$; Fig. 2; SI). The water column structure at St. 6, as with much of the $40^{\circ} \mathrm{S}$ transect, is dominated by the north- and southward advection of water masses that formed at higher latitudes (Fig. 3). Surface waters are a mixture between north-flowing SASW (Sub-Antarctic Surface Water) and south-flowing STSW (Sub-Tropical Surface Water), with surface water macronutrient concentrations significantly greater in SASW than in STSW. Below the surface, northward-flowing AAIW (Antarctic Intermediate Water) is evident around $\approx$ $600 \mathrm{~m}$ from the distinct salinity minimum $(\sim 34.3)$, as is the core of southward-flowing UCDW (Upper Circumpolar Deep Water) at $1,500 \mathrm{~m}$, which is picked out by the higher macronutrient concentrations (e.g. $\mathrm{PO}_{4}^{3-}>2 \mu \mathrm{M}$ ) and low $\left[\mathrm{O}_{2}\right]$. Salinities $>34.8$ and lower macronutrient concentrations between $\approx 2,000-3,500 \mathrm{~m}$ are indicative of the southward flow of NADW (North Atlantic Deep Water), whilst abyssal depths are dominated by north-flowing nutrient-rich AABW (Antarctic Bottom Water; Figs. 2 and 3). From the complete profile, 13 samples were selected for analysis so as to include at least one representative end-member from each water mass. 


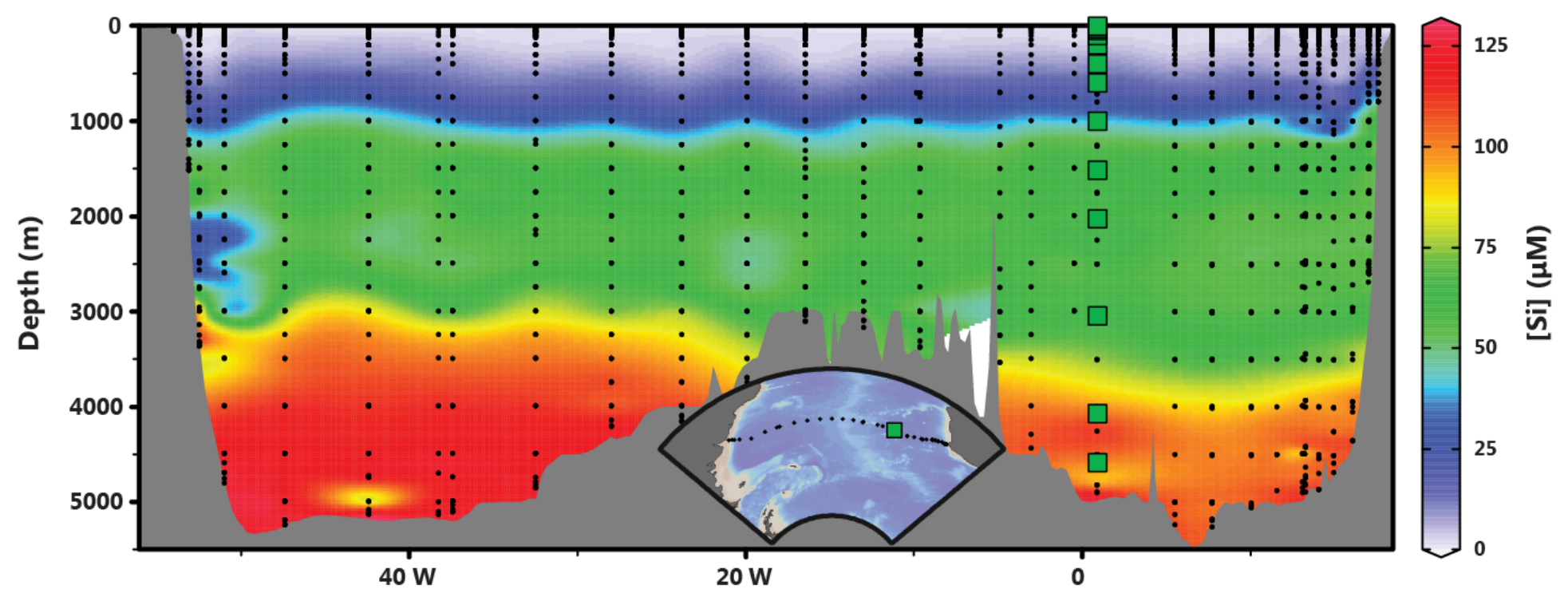

Figure 2: Map showing sampling locations along UK-GEOTRACES $40{ }^{\circ} \mathrm{S}$. The main panel displays a section of dissolved [Si] (dots) measured during GA10W (JC068; inset), which sailed east-west along $40^{\circ} \mathrm{S}$ from Cape Town (ZAF)-Montevideo (URY). Squares mark the location and depths of the samples analyzed in this study, which were collected at St. 6 of GA10E (D357) approximately one year prior to GA10W. Figure drafted in Ocean Data View.

Seawater samples were collected as part of the first UK GEOTRACES $40^{\circ} \mathrm{S}$ South Atlantic zonal transect in October 2010 (GA10E/D357; Fig. 2). Seawater was sampled using a PTFE-coated OTE (Ocean Test Equipment) $24 \times 10 \mathrm{~L}$ bottle CTD system on a 'trace metal-free' Ti rosette, deployed from a plasma rope. Following collection, OTE bottles were brought into a clean sampling container for further processing. Water samples were filtered through a $0.2 \mu \mathrm{m}$ filter capsule and transferred into 1 L HDPE bottles, sealed, and stored inside two zipper storage bags out of direct sunlight. Samples were acidified to $\mathrm{pH} \sim 2$ by addition of $2.4 \mathrm{~mL}$ of $10 \mathrm{M} \mathrm{HCl}$ at the NIRVANA laboratory at WHOI (Woods Hole Oceanographic Institution), and subsequently left to equilibrate for several days before any sample processing took place.

\subsection{Overview of Ba-isotopic method}

A brief overview of the methodology is provided here, though a full description of all procedures is provided in the SI, along with discussion relating to measurement precision and accuracy. Precise Ba-isotopic measurements can be achieved on samples containing as little as $\sim 10 \mathrm{ng}$ Ba using our new double spike method, although the smallest amount of Ba encountered here was $\sim 30 \mathrm{ng}$. We opted to use a double spike procedure, as opposed to standard-sample bracketing or external normalization, to avoid any potential Ba-isotopic fractionations associated with minor Ba losses during Ba purification from seawater. A double spike also has the added benefit of improving the signal : noise ratio of the mass spectrometric analyses, as samples contain both sample- and spike-derived Ba.

After spiking samples, Ba was purified from the seawater matrix before mass spectrometric analysis. Barium was pre-concentrated from seawater using a $(\mathrm{Ba}, \mathrm{Ca}) \mathrm{CO}_{3}$ co-precipitation, based on a scaled-down version of the procedure described by Foster et al. (2004), and samples twice passed through liquid cation-exchange chromatographic columns (e.g. Wolgemuth and Broecker, 1970). Isotopic analyses were performed at the WHOI Plasma Mass Spectrometry Facility on a Neptune multiple-collector inductively-coupled plasma mass spectrometer (see SI for details). All sample Ba-isotopic compositions are reported in the $\delta$-notation (\%o) relative to the measured 'daily offset' (e.g. Dideriksen et al., 2006) value of National Institute of Standards and Technology (NIST) Ba Standard Reference Material 3104a: 


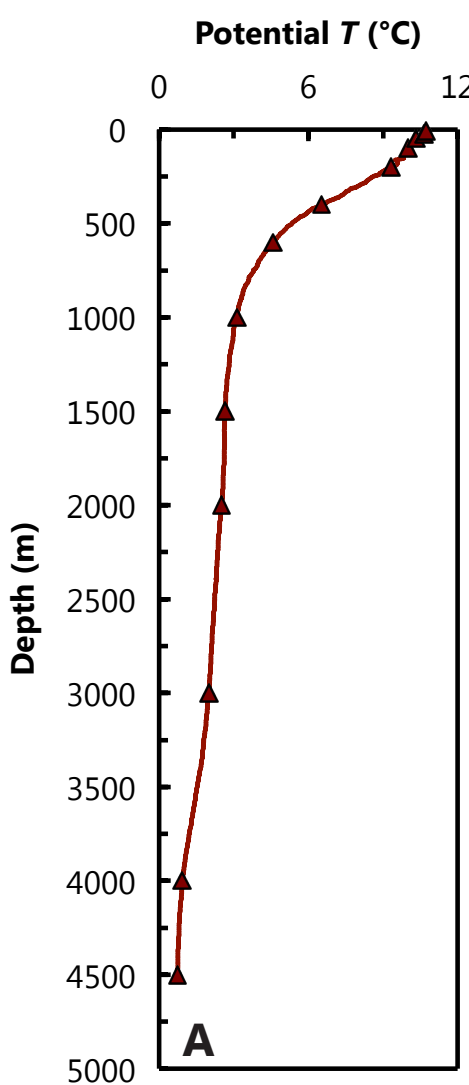

[Phosphate] $(\mu \mathrm{M})$

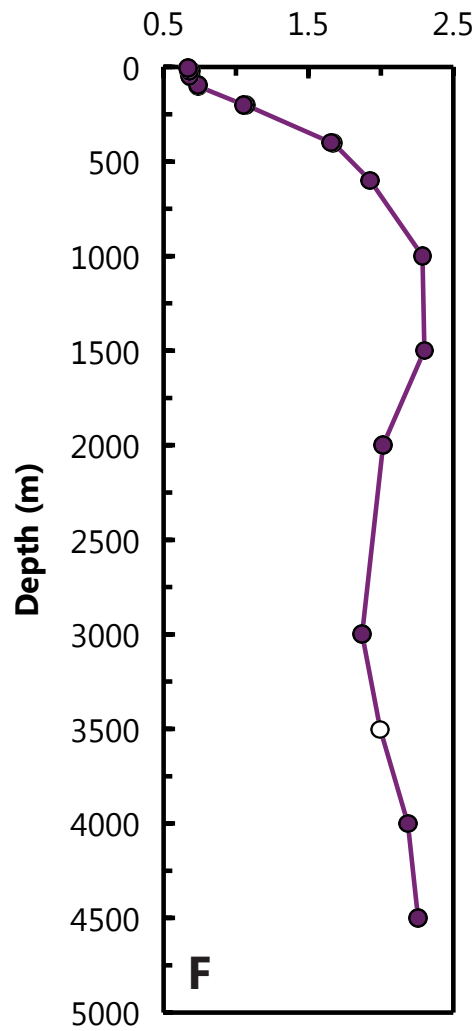

Salinity (PSU)

$12 \quad 34.0$

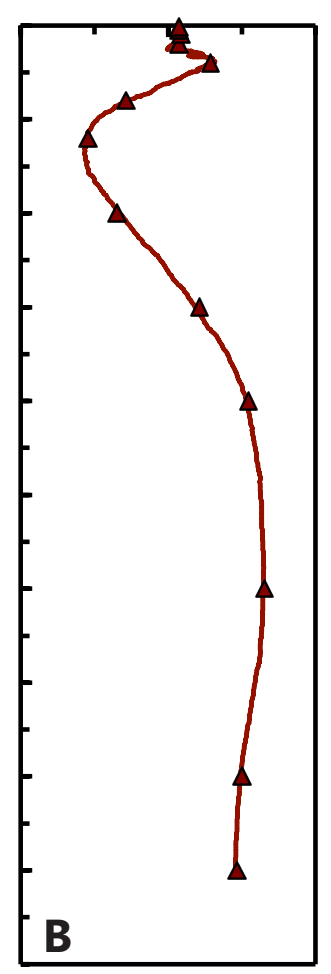

[Nitrate] $(\mu \mathrm{M})$

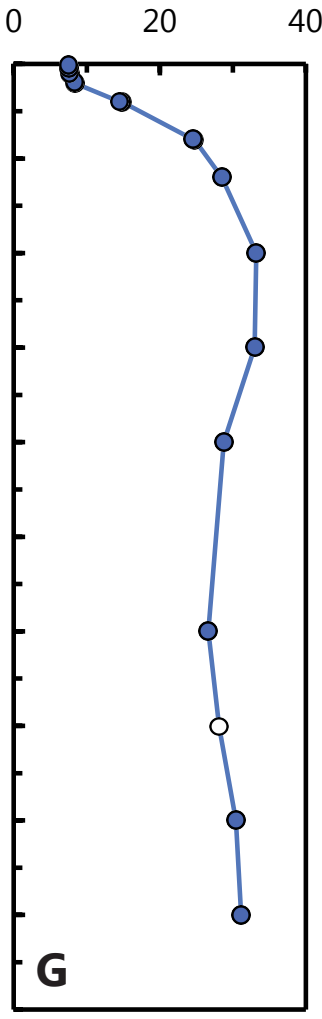

$\left[\mathrm{O}_{2}\right](\boldsymbol{\mu M})$

$150 \quad 200 \quad 250$

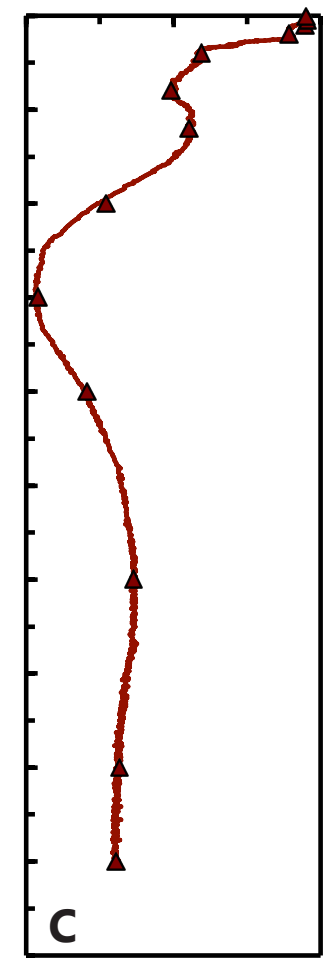

[Silicate] $(\mu \mathrm{M})$

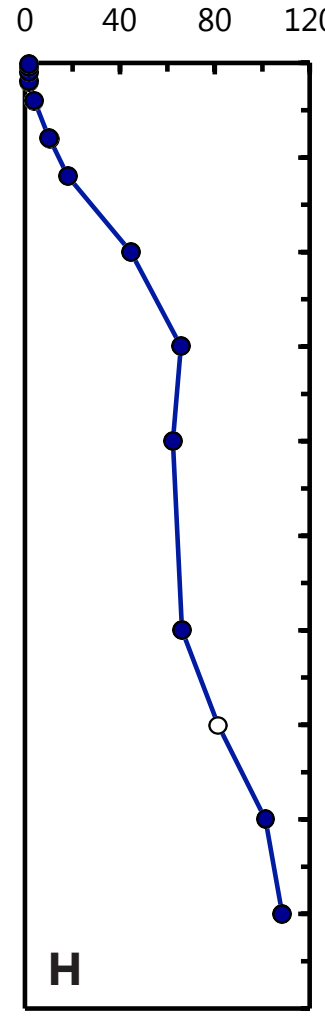

Fluorescence (rel.)

$0.0 \quad 0.5 \quad 1.0$

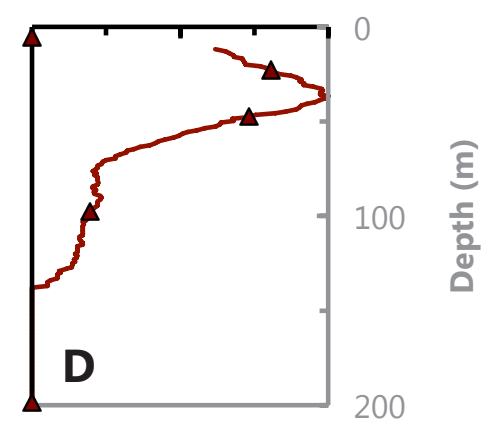

Transmission (rel.)
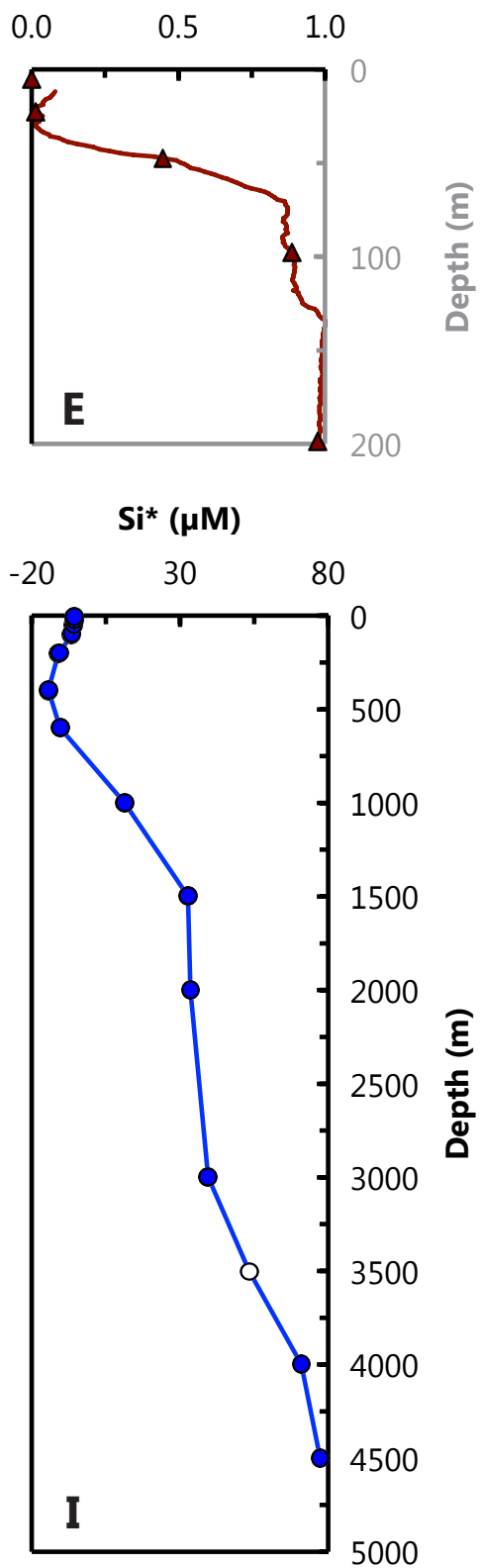

Figure 3: Hydrography at Station 6. Solid and open symbols denote samples that were and were not analyzed for dissolved [Ba] and Baisotopic compositions, respectively (Fig. 4). Depth profiles of A potential temperature, B salinity, C dissolved oxygen, D relative chlorophyll fluorescence (note change in depth scale), E relative transmittance $\left(\lambda=660 \mathrm{~nm}\right.$; note change in depth scale), $\mathbf{F}$ dissolved $\left[\mathrm{PO}_{4}^{3-}\right], \mathbf{G}^{-}$dissolved $\left[\mathrm{NO}_{3}^{-}\right], \mathbf{H}$ dissolved $\left[\mathrm{Si}(\mathrm{OH})_{4}\right]$, and $\mathbf{I} \mathrm{Si}^{*}$, a tracer of diatom nutrient status (where $\mathrm{Si}^{*}=[\mathrm{Si}]-\left[\mathrm{NO}_{3}^{-}\right]$; Sarmiento et al., 2004). 


$$
\delta^{138 / 134} \mathrm{Ba}_{\text {NIST }}=\left(\frac{{ }^{138} \mathrm{Ba}^{134} \mathrm{Ba}_{\text {sample }}}{{ }^{138} \mathrm{Ba} /{ }^{134} \mathrm{Ba}_{\text {NIST SRM 3104a }}}-1\right) \times 1,000
$$

Previous studies have reported Ba-isotopic compositions as $\delta^{137 / 134} \mathrm{Ba}$, which can be converted to $\delta^{138 / 134} \mathrm{Ba}_{\mathrm{NIST}}$ by multiplying by $\approx 1.33$, assuming the samples being compared were also measured against NIST SRM 3104a. Sample uncertainties are reported as the larger of either the long-term $2 \times$ Standard Deviation (SD) of replicate analyses of JCp-1 $\left(\delta^{138 / 134} \mathrm{Ba}_{\mathrm{NIST}}=+0.29 \pm 0.03 \%\right.$ o $)$ or the $\pm 2 \times$ Standard Error $(\mathrm{SE})$ uncertainty measured on any given sample. This approach is justified by the excellent agreement between replicate analyses of GEOTRACES sample No. 435 $(600 \mathrm{~m})$ and the Ba-isotopic similarity of the upper $200 \mathrm{~m}( \pm 0.02 \%)$. The procedural blank was determined to be $1.1 \mathrm{ng} \mathrm{Ba}( \pm 2 \%)$ with $\delta^{138 / 134} \mathrm{Ba}_{\mathrm{NIST}}=-0.17 \pm 0.18 \%$ o $( \pm 2 \mathrm{SE})$, which was $<4 \%$ of the total Ba present in the seawater with the lowest [Ba]. Given the Ba-isotopic composition of the blank, this level of contamination can only shift sample Ba-isotopic compositions by a maximum of $\pm 0.01 \%$, which is within the long-term uncertainty of $\pm 0.03 \%$ (see SI for discussion of long-term uncertainties). As such, the blank correction was only applied to the Ba-concentration data obtained by isotopic dilution, but not the Ba-isotopic data.

\section{Results}

The profile data show clear and systematic changes in [Ba] (Fig. 4a) and $\delta^{138 / 134} \mathrm{Ba}_{\mathrm{NIST}}$ (Fig. 4b) that correspond to the major features of the dissolved [Si] profile (Fig. 3h), albeit with some subtle - but important - differences. Dissolved [Ba] ranges from $43.6-99.9 \mathrm{nM}$ and $\delta^{138 / 134} \mathrm{Ba}_{\mathrm{NIST}}$ from +0.29 to $+0.60 \%$; Ba-isotopic variation is $\approx 5$ times greater than our $\pm 2 \mathrm{SD}$ long-term measurement precision of $\pm 0.03 \%$. The data show a general increase in [Ba] and decrease in $\delta^{138 / 134} \mathrm{Ba}_{\text {NIST }}$ with depth, typical of other nutrient-type elements in seawater (e.g. N, Si, or Cd; de Souza et al., 2012; Xue et al., 2013). The main deviation from these otherwise monotonic trends occurs between 1,500-3,000 m, whereby [Ba] mimics the slight decrease seen in the algal macronutrients as the profile passes through those depths influenced by nutrient-poor NADW (Fig. 3); a minor decrease in [Ba] of $2.0 \mathrm{nM}$ is also seen between 4,000 - 4,500 m that is not reflected in the macronutrient concentrations. In both instances, there is a small $(\leq+0.03 \%)$ increase in Ba-isotopic compositions associated with each decrease in [Ba], suggesting that there is a tight coupling between [Ba] and $\delta^{138 / 134} \mathrm{Ba}_{\mathrm{NIST}}$ throughout the water column. At depths corresponding to AABW below $\approx 3,500 \mathrm{~m}$, where [Ba] reaches a maximum of almost $\approx 100 \mathrm{nM}$, dissolved $\delta^{138 / 134} \mathrm{Ba}_{\mathrm{NIST}}$ reaches a minimum of $\approx+0.3 \%$, producing a tight linear array between dissolved $\delta^{138 / 134} \mathrm{Ba}_{\mathrm{NIST}}$ and [Ba] (Fig. 5).

Despite the similarities between [Ba], $\delta^{138 / 134} \mathrm{Ba}_{\mathrm{NIST}}$, and the algal macronutrients, two subtle depth-dependent differences are evident. The first of these differences is that dissolved [Ba] and $\delta^{138 / 134} \mathrm{Ba}_{\mathrm{NIST}}$ are essentially invariant with respect to depth between the surface and $\approx 200 \mathrm{~m}:[\mathrm{Ba}]=43.9 \pm 0.5 \mathrm{nM}$ and $\delta^{138 / 134} \mathrm{Ba}_{\mathrm{NIST}}=$ $+0.59 \pm 0.02 \%$ o $( \pm 2 \mathrm{SD}$; see insets in Fig. 4). In contrast to $\mathrm{Ba}$, other nutrient-type elements such as $\mathrm{N}, \mathrm{Si}$, or $\mathrm{Cd}$ show essentially monotonic decreases in their concentrations and increases in their isotopic compositions, reaching their respective extrema at the very surface (e.g. Sigman et al., 1999; de Souza et al., 2012; Xue et al., 2013). This near-surface invariance may also be related to the second major difference between [Ba] and other algal macronutrients, which is that Ba concentrations are very rarely significantly depleted at the surface relative to the base of the thermocline (Fig. 4). As can be seen from the regional [Ba]-[Si] compilation (Fig. 1) and here at St. 6 (Figs. 3h and 4a), dissolved $\mathrm{Ba}$ concentrations rarely dip below $40 \mathrm{nM}$, even for waters that have experienced near-quantitative Si removal. As such, $\delta^{138 / 134} \mathrm{Ba}_{\mathrm{NIST}}$ at $200 \mathrm{~m}$ is statistically indistinguishable from that at $5 \mathrm{~m}(\approx+0.6 \%$ o $)$, whereas dissolved N-, Si- or Cd-isotopic compositions may increase by several permil over the same interval. Both of these patterns are consistent with previous observations from the South Atlantic (e.g. Chan et al., 1977), and our data confirm that these large-scale distributions seen for [Ba] are also reflected in $\delta^{138 / 134} \mathrm{Ba}_{\mathrm{NIST}}$. 


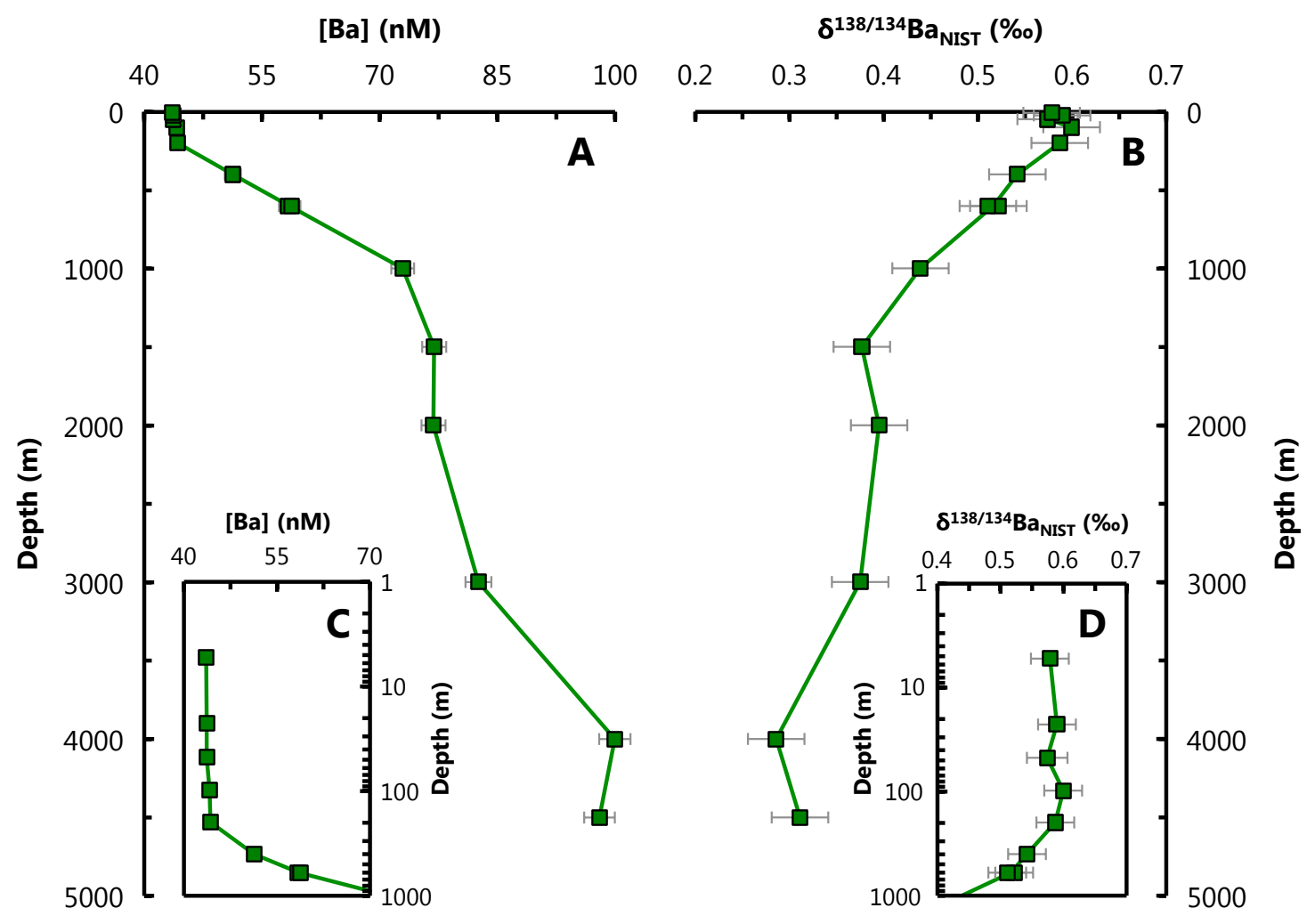

Figure 4: Ba concentration and isotopic data from the South Atlantic. A Complete [Ba] and B Ba-isotopic depth profiles from Station 6 $\left(0.92^{\circ} \mathrm{E} ; 39.99^{\circ} \mathrm{S}\right)$. Insets $\mathbf{C}$ and $\mathbf{D}$ show the upper $1,000 \mathrm{~m}$ in greater detail owing to the higher sampling density at these depths. In this, and subsequent Figs., the solid line passes through the arithmetic mean of the replicate samples at $600 \mathrm{~m}$ (\# 635).

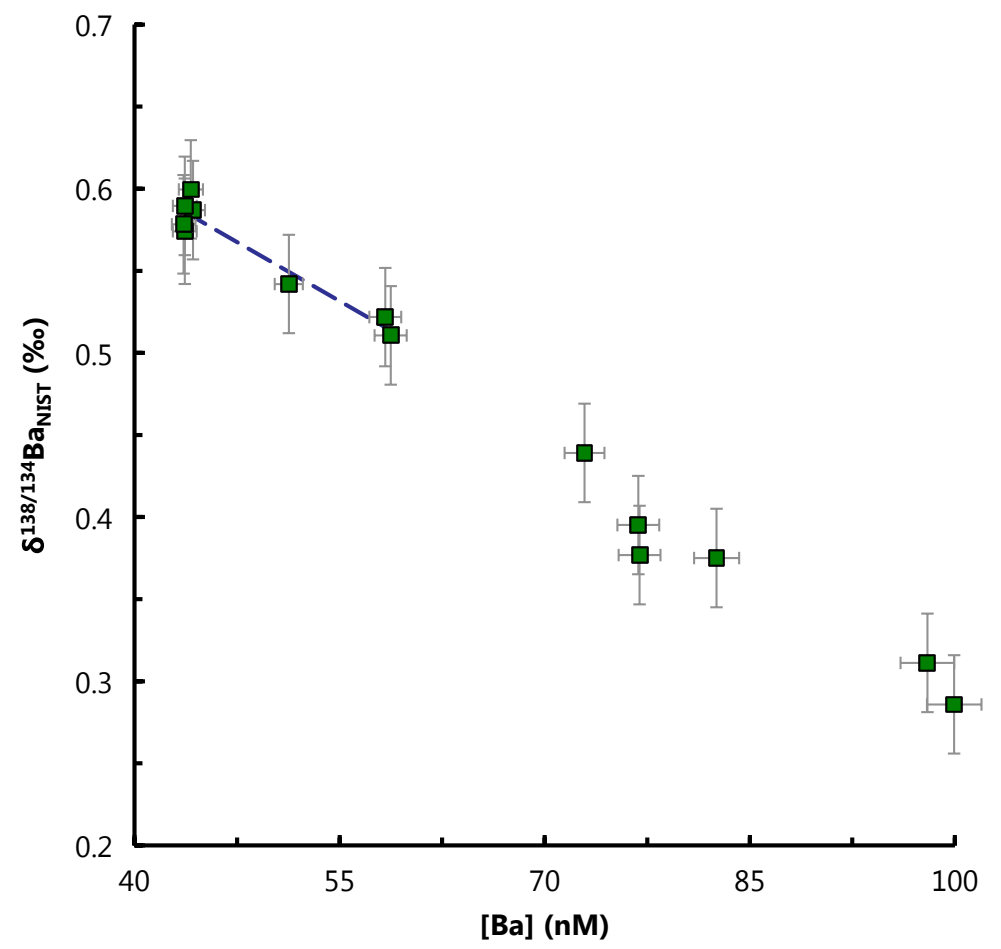

Figure 5: Relationship between Ba-isotopic compositions at [Ba] at St. 6. The upper $600 \mathrm{~m}$ of the profile have been fitted using a York Regression to yield an approximate Ba-isotopic fractionation factor for $\mathrm{BaSO}_{4}$ precipitation in the thermocline (see Sec. 4.2 .2 for related discussion). 


\section{Discussion}

In the following sections, co-located measurements of $[\mathrm{Ba}], \delta^{138 / 134} \mathrm{Ba}_{\mathrm{NIST}}$, and a new tracer, $\mathrm{Ba}^{*}$ are used to refine our insights into the biogeochemical and circulation processes that govern marine Ba distributions. We focus these insights primarily on disentangling regional biogeochemical and circulation features from those processes that are unique to Ba cycling using novel constraints from $\mathrm{Ba}^{*}$ and $\delta^{138 / 134} \mathrm{Ba}_{\mathrm{NIST}}$, respectively.

\subsection{Tracing Ba and Si decoupling in the water column using $\mathrm{Ba}^{*}$}

Though the major concentration and isotopic gradients for nutrient-type elements are set by biogeochemical processes occurring in the near surface, dissolved nutrients are continuously added by remineralization as water masses age along their flowpaths (e.g. Broecker and Peng, 1982). Thus, at any given depth, the total nutrient inventory and its isotopic composition - represents a sum of the regenerated- and preformed-nutrient components. Both components are sourced from the surface, though the preformed component is brought into the ocean interior through circulation, whereas the regenerated component is added through the remineralization of sinking particles. This important distinction is most easily conceptualized using a derived tracer based on the comparison of two nutrient-like elements. The numerical values of these derived tracers are invariant so long as the uptake and regeneration ratio of the two elements being compared remains constant during biogeochemical cycling (e.g. $\mathrm{N}$ and $\mathrm{P}$ for $\mathrm{N}^{*}$, Si and $\mathrm{N}$ for $\mathrm{Si}^{*}$, Gruber and Sarmiento, 1997; Sarmiento et al., 2004). Since these uptake and regeneration ratios do exhibit some spatial variability in the near-surface, these derived quantities are powerful tracers of biogeochemical cycling and oceanic circulation (e.g. Sarmiento et al., 2007). Thus, to aid interpretation of our Ba-isotopic profile, we define an analogous tracer - $\mathrm{Ba}^{*}$ - for probing marine Ba cycling, which is premised on the close correlation between [Ba] and [Si] seen throughout the South Atlantic (and elsewhere; e.g. Fig. 1; Chan et al., 1977).

Despite the close correlation between [Ba] and [Si] in the South Atlantic, there are subtle deviations from perfectly linear behavior (Fig. 1). These deviations should be expected a priori, as the controls on Ba and Si uptake and removal from seawater are fundamentally different. Barium distributions are thought to be primarily driven by the precipitation of $\mathrm{BaSO}_{4}$ in near-surface seawater - rather than through direct incorporation into either organic matter or $\mathrm{CaCO}_{3}$ (e.g. Dehairs et al., 1980; Sternberg et al., 2005; Sec. 4.2.1) - followed by dissolution in the water column, which is under-saturated with respect to $\mathrm{BaSO}_{4}$ (with the exception of the upper $\sim 1,500 \mathrm{~m}$ of the Atlantic Sector of the high latitude Southern Ocean; Monnin et al., 1999). In contrast, Si distributions are known to be driven almost exclusively by diatom opaline $\mathrm{SiO}_{2}$ precipitation and subsequent dissolution in the $\mathrm{SiO}_{2}$-undersaturated water column (e.g. Broecker and Peng, 1982). Thus, the mechanism(s) underpinning the linear [Ba]-[Si] correlation in seawater demand explanation. To quantify these deviations from perfect [Ba]-[Si] coupling, we define a new tracer, $\mathrm{Ba}^{*}$ using a subset of the South Atlantic [Ba]-[Si] data located between $0-50^{\circ} \mathrm{S}$ (Fig. 1):

$$
\mathrm{Ba}^{*}=[\mathrm{Ba}]_{\text {meas. }}-0.52 \times[\mathrm{Si}]_{\text {meas. }}-43.9
$$

where $\mathrm{Ba}^{*},[\mathrm{Ba}]_{\text {meas., }}$ and $[\mathrm{Si}]_{\text {meas. }}$ have units of $\mathrm{nM}, \mathrm{nM}$, and $\mu \mathrm{M}$, respectively. Absolute values of Ba* are essentially arbitrary, since different water masses likely possess different preformed $\mathrm{Ba}^{*}$ values. Thus, depth profiles of $\mathrm{Ba}^{*}-\mathrm{as}$ for those of $\mathrm{N}^{*}$ (Gruber and Sarmiento, 1997) - are best interpreted in terms of deviations from invariant behavior. The magnitude and direction of these deviations will depend on the net effects of $\mathrm{BaSO}_{4}$ precipitation and $\mathrm{SiO}_{2}$ dissolution (more negative $\mathrm{Ba}^{*}$ ) compared with $\mathrm{BaSO}_{4}$ dissolution and $\mathrm{SiO}_{2}$ precipitation (more positive Ba*) relative to the mean South Atlantic trend defined in Eq. 2.

Paired measurement of dissolved $\delta^{138 / 134} \mathrm{Ba}_{\mathrm{NIST}}$ and $\mathrm{Ba}^{*}$ should assist in parsing the depth-dependent variations in $\mathrm{Ba}^{*}$ into its constituent $\mathrm{BaSO}_{4}$ - and $\mathrm{SiO}_{2}$-cycling components, respectively. Experimental and theoretical studies showed that precipitation of $\mathrm{BaSO}_{4}$ favors incorporation of isotopically-light Ba (Von Allmen et al., 2010; Hofmann 


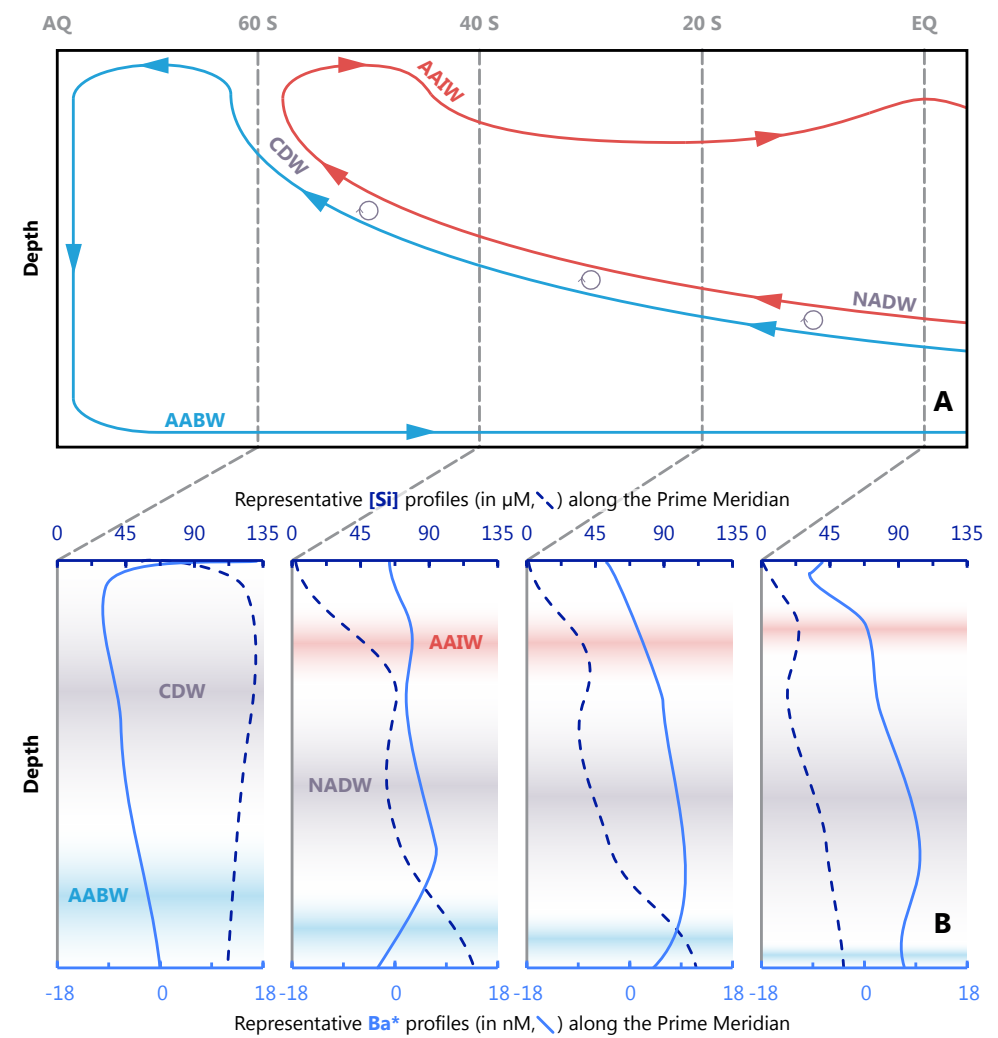

Figure 6: Conceptual model for linking ocean circulation, Si, and Ba cycling in the South Atlantic. A Cartoon showing the two major circulation patterns along the Prime Meridian (AQ, Antarctica; EQ, Equator; adapted from de Souza et al., 2012). B Smoothed depth profiles of [Si] and Ba* at 60, 40, $20^{\circ} \mathrm{S}$, and the Equator, derived from profile data at Stations 89, 93, 103, 111 of the Atlantic GEOSECS Expeditions, respectively (e.g. Chan et al., 1977).

et al., 2012), which would render residual Ba dissolved in solution isotopically heavy. Though currently unconstrained, it is reasonable to assume that diatom $\mathrm{SiO}_{2}$ precipitation has a relatively minor effect on dissolved Baisotopic compositions in seawater, as $\mathrm{SiO}_{2}$ is not a significant particulate $\mathrm{Ba}$ vector compared to $\mathrm{BaSO}_{4}$ (e.g. Dehairs et al., 1980; Sternberg et al., 2005; Sec. 4.2.1). This assumption does not preclude any Ba-isotopic fractionation between dissolved $\mathrm{Ba}$ in seawater and $\mathrm{Ba}$ associated with organic matter, merely that the decrease in the dissolved Ba inventory - and therefore any changes in dissolved $\delta^{138 / 134} \mathrm{Ba}_{\mathrm{NIST}}$ - resulting from organic matter cycling are very small compared to those driven by $\mathrm{BaSO}_{4}$ cycling. Thus, dissolved Ba-isotopic compositions should be primarily sensitive to $\mathrm{BaSO}_{4}$ cycling, whereas $\mathrm{Ba}^{*}$ is sensitive to both $\mathrm{SiO}_{2}$ and $\mathrm{BaSO}_{4}$ cycling. This distinction is important, as depth-dependent variations in $\mathrm{Ba}^{*}$ and $\delta^{138 / 134} \mathrm{Ba}_{\text {NIST }}$ should help to identify the processes responsible for [Ba]-[Si] decoupling.

To aid interpretation of the new $\mathrm{Ba}^{*}$ data from St. 6, we also determined depth profiles of $\mathrm{Ba}^{*}$ at other localities in the South Atlantic using literature data (Fig. 6; Chan et al., 1977). These profiles illustrate how primary productivity, remineralization, and oceanic circulation modulate the basin-scale distributions of $\mathrm{Si}, \mathrm{Ba}$, and $\mathrm{Ba}^{*}$. Three major features are evident: (1) markedly different $\mathrm{Ba}^{*}$ distributions in the high latitude Southern Ocean compared to the lower latitudes; (2) increases in the Ba* contrast between the very surface and the core of AAIW and (3) a smoothing of the $\mathrm{Ba}^{*}$ contrast between NADW and AABW towards the Equator. We briefly outline each of these features before discussing $\mathrm{Ba}^{*}-\mathrm{Ba}$-isotopic relationships at St. 6 .

At $60^{\circ} \mathrm{S}$, elevated values of $\mathrm{Ba}^{*}$ are seen in surface waters, likely resulting from intense Si removal by diatoms, coupled to a comparatively smaller drawdown in the dissolved [Ba] inventory (e.g. Chan et al., 1977). Ba* decreases sharply below the very surface as organic matter is remineralized (increasing [Si]) and $\mathrm{BaSO}_{4}$ precipitated, imparting extremely low $\mathrm{Ba}^{*}$ on subsurface southward-flowing CDW. As noted above, the processes responsible for organic matter remineralization and $\mathrm{BaSO}_{4}$ precipitation may be mechanistically coupled (e.g. González-Muñoz et al., 2003; Ganeshram et al., 2003). The northward flow of AABW at the base of the profile exhibits slightly higher Ba* than 
overlying waters, suggesting additional inputs of $\mathrm{Ba}$ - relative to $\mathrm{Si}$ - to this water mass as it travels through the southern loop of Antarctic circulation (Fig. 6). These additional Ba inputs could originate from increased $\mathrm{BaSO}_{4}$ dissolution, either in the $\mathrm{BaSO}_{4}$-undersaturated water column below 1,500 m (Monnin et al., 1999) or from sedimentary $\mathrm{BaSO}_{4}$ deposited along the Antarctic shelf (e.g. Hoppema et al., 2010).

The near-quantitative removal of Si from CDW in the Polar Front Zone imparts elevated Ba* to northward-flowing water masses such as AAIW and SAMW (Subantarctic Mode Water). Since these water masses sit just below or at the base of the South Atlantic thermocline (Sarmiento et al., 2004), the starting Ba* of the upper water column at $40^{\circ} \mathrm{S}$ appears to be dictated by processes affecting SAMW in the Southern Ocean (Fig. 4). Indeed, there is an appreciable maximum in Ba* that is associated with the core of AAIW that can be seen throughout the South Atlantic (Fig. 6b). Values of $\mathrm{Ba}^{*}$ are generally lower at the very surface compared with the core of AAIW, likely reflecting near-surface $\mathrm{BaSO}_{4}$ production, with this gradient increasing towards the Equator. This regional pattern probably reflects both the high amounts of $\mathrm{BaSO}_{4}$ production and sedimentation in the Equatorial belts (e.g. Schmitz, 1987), superimposed atop the progressive depletion of Ba from the northward-flowing Si-poor waters that feed low latitude thermoclines.

In the deep equatorial Atlantic, the Ba* gradient between NADW and AABW diminishes (Fig. 6). This is suggestive of both a waning contribution of AABW to abyssal waters at lower latitudes, as well as deep ocean mixing gradually smoothing out the water mass signals evident in both $\mathrm{Ba}^{*}$ and [Si] seen at the higher latitudes. Despite this smoothing between the deep waters, the $\mathrm{Ba}^{*}$ gradient between NADW and surface waters is greatest at the Equator. This may reflect increased remineralization of Ba relative to $\mathrm{Si}$ - most likely from $\mathrm{BaSO}_{4}$ dissolution - in Si-poor south-flowing NADW, as well as reflecting the aforementioned progressive depletion of Ba from northward-flowing near-surface waters. Overall, the depth profiles of $\mathrm{Ba}^{*}$ in the South Atlantic are thus more nuanced than the simple linear correlation between [Ba] and [Si] (Fig. 1), and is closer to our initial expectation of mechanistically-uncoupled $\mathrm{Ba}$ and Si cycling in the region. With the regional context in place we now turn our focus back to St. 6.

\subsection{Origin of Ba-isotopic variations in seawater}

\subsubsection{Organic matter or barite?}

The persistence of distinct $\mathrm{Ba}^{*}$ features across large distances within the ocean interior indicates that preformed water mass signals are important components of the [Ba] and Ba-isotopic depth structure at St. 6. Given that these $\mathrm{Ba}^{*}$ features likely originated at or near the surface it is worthwhile to consider the relative importance of two important phases that cycle particulate $\mathrm{Ba}$ : organic matter and $\mathrm{BaSO}_{4}$. Since the presence of acantharia are not necessarily a strict requirement for large Ba drawdowns (e.g. Esser and Volpe, 2002), they are not considered in the following discussion.

We estimated the proportion of Ba cycled directly by phytoplankton organic matter by first estimating the proportions of preformed and regenerated nutrients at St. 6 as per Broecker and Peng 1982, using an apparent oxygen utilization : phosphorus stoichiometry of $170: 1$. 'Regenerated' Ba was subsequently calculated from regenerated phosphate by assuming a fixed $\mathrm{Ba}: \mathrm{P}$ stoichiometry in marine phytoplankton of $1.1 \mathrm{mM}: \mathrm{M}$, which is representative of near-surface marine particles (e.g. Bishop and Wood, 2008). Since it is unclear if Ba cycled by algal organic matter is truly incorporated or passively adsorbed, we term this Ba pool 'phytoplankton associated' (e.g. Sternberg et al., 2005). Further, the true ratio of algal Ba : P is debated: cultures of Thalassiosira weissflogii yield Ba : $\mathrm{P}$ of $0.5 \mu \mathrm{M}: \mathrm{M}$ (Sternberg et al., 2005), whereas near-surface marine particulate matter is often characterized by a $\mathrm{Ba}: \mathrm{P}$ of $\approx 1 \mathrm{mM}: \mathrm{M}$ (e.g. Bishop and Wood, 2008). This 2,000-fold discrepancy between Ba : P determined from culture and field measurements may reflect the presence of $\mathrm{Ba}$ in $\mathrm{BaSO}_{4}$ crystals as well as associated with organic matter in near-surface particulate samples (Bishop, 1988). In situ particulate Ba : $\mathrm{P}$ are thus potentially biased toward higher 'cellular' concentrations than cultures, such that the contribution from organic matter may be substantially lower than that estimated here. Regardless of the assumed $\mathrm{Ba}: \mathrm{P}$ however, the proportion of algal organic matterassociated regenerated $\mathrm{Ba}$ in the water column is extremely small, ranging from less than $0.01 \%$ up to $\approx 1.5 \%$ for 
$\mathrm{Ba}$ : P between $0.5 \mu \mathrm{M}: \mathrm{M}$ and $1.1 \mathrm{mM}: \mathrm{M}$, respectively (see SI). As expected, this exercise confirms that the stoichiometric cycling of Ba associated with organic matter is not a substantial driver of [Ba] - and by inference, Ba-isotopic - cycling in the water column.

The analysis presented above strongly suggests that organic matter-associated Ba contributes relatively little to the large-scale distributions of $\mathrm{Ba}$ in seawater. However, this analysis does not consider $\mathrm{Ba}$ associated with $\mathrm{BaSO}_{4}$ cycling, which likely is the dominant vector of particulate Ba to the ocean interior (e.g. Dehairs et al., 1980). Furthermore, the microbial processes responsible for the remineralization of organic matter appear related - if not coupled - to the precipitation of particulate $\mathrm{BaSO}_{4}$ in marine particulate matter (e.g. Chow and Goldberg, 1960): as algal macronutrients are returned to seawater, $\mathrm{Ba}$ is removed. Thus, the true contribution of regenerated $\mathrm{Ba}$ from $\mathrm{BaSO}_{4}$ dissolution cannot be robustly estimated using the reverse Redfield-Ketchum-Richards equation, as remineralization of $\mathrm{BaSO}_{4}$-associated $\mathrm{Ba}$ is non-stoichiometric with respect to the algal macronutrients. This lack of a stoichiometric relationship necessitates an alternative method, such as paired measurements of $\delta^{138 / 134} \mathrm{Ba}_{\mathrm{NIST}}$ and $\mathrm{Ba}^{*}$, to constrain the proportion of Ba cycling associated with $\mathrm{BaSO}_{4}$, which is discussed in the following section.

Lastly, it is important to stress that this analysis does not preclude organic matter-associated Ba from being a quantitatively-significant intermediate source of $\mathrm{Ba}$ to marine $\mathrm{BaSO}_{4}$ formation, only that organic matter itself is likely not responsible for the large-scale distributions of $\mathrm{Ba}$ in the ocean. The formation of marine $\mathrm{BaSO}_{4}$ appears to be critically dependent on the presence of heterotrophic bacteria, which play a key role in the degradation of POC in seawater (particulate organic carbon; e.g. Bertram and Cowen, 1997; González-Muñoz et al., 2003; Ganeshram et al., 2003; González-Muñoz et al., 2012). The majority of these heterotrophic microbes live within $100 \mathrm{~m}$ of the base of the euphotic zone where the supply of phytoplankton-derived organic matter is highest (e.g. Herndl and Reinthaler, 2013). Thus, in addition to $\mathrm{Ba}$ in $\mathrm{BaSO}_{4}$ sourced from dissolved $\mathrm{Ba}^{2+}$ in seawater - the ultimate $\mathrm{Ba}$ source in marine $\mathrm{BaSO}_{4}$ - it is reasonable to assume that some fraction of the $\mathrm{Ba}$ in $\mathrm{BaSO}_{4}$ is also sourced from that originally associated with phytoplankton organic matter (Fig. 7), particularly so in regions where significant quantities of POC are remineralized rather than exported to the seafloor. Should these two different sources of Ba to marine $\mathrm{BaSO}_{4}$ possess distinct $\delta^{138 / 134} \mathrm{Ba}_{\mathrm{NIST}}$, the net Ba-isotopic composition of seafloor $\mathrm{BaSO}_{4}$ will be sensitive, in part, to the balance between the two Ba sources that are incorporated during $\mathrm{BaSO}_{4}$ precipitation (Fig. 7). The possibility of such a relationship, though speculative, represents an extremely promising target for future Ba-isotopic studies in the marine realm as a potential means to study POC remineralization in the modern and paleo-oceans.

\subsubsection{Clues to the depth range of barite cycling}

In this section, we examine variation in $\mathrm{Ba}^{*}$ and $\mathrm{Ba}$-isotopic compositions to place approximate constraints on the depth range over which the process of $\mathrm{BaSO}_{4}$ precipitation is imprinted on the water column. Such constraints are clearly required, as there are still significant discrepancies between the $\mathrm{BaSO}_{4}$ formation depths inferred from different analytical approaches. For example, the sharp increase in particulate Ba concentrations coincident with the dissolved oxygen minimum has been interpreted as evidence of shallow $\mathrm{BaSO}_{4}$ formation in bioaggregate-associated microenvironments (i.e. $\leq 200 \mathrm{~m}$ depth; e.g. Dehairs et al., 1990). As these aggregates are broken down, the enclosed $\mu \mathrm{m}$-sized $\mathrm{BaSO}_{4}$ crystals are released into seawater, leading to the characteristic maximum in particulate Ba abundances between 200 - 600 m (e.g. Bishop, 1988; Stroobants et al., 1991; Jacquet et al., 2005). In contrast, radiumisotopic analyses of sinking particulates from the Sargasso Sea indicate that $\mathrm{BaSO}_{4}$ formation occurs continually with depth to 3,200 m, or that $\mathrm{BaSO}_{4}$ pumping to depth is extremely rapid (Van Beek et al., 2007). Paired profile data of $\mathrm{Ba}^{*}$ and $\mathrm{Ba}$-isotopic compositions can be used to place some constraints on the depth ranges over which the influence of these processes are recorded in seawater, as Ba* is affected by both $\mathrm{Ba}$ and Si cycling, whereas dissolved $\delta^{138 / 134} \mathrm{Ba}_{\text {NIST }}$ is only sensitive to those processes that cycle Ba.

The depth profile of $\mathrm{Ba}^{*}$ at St. 6 exhibits numerous reversals with depth where the inflection points appear to correspond to cores of major water masses encountered by the profile (Fig. 8a). Ba* is essentially invariant between $5-200 \mathrm{~m}$, but sharply increases towards the core of AAIW at $600 \mathrm{~m}$, a feature that is also seen in the regional profiles (Fig. 6). Inflection points are also seen at 1,500 $\mathrm{m}$ (CDW) and 3,000 $\mathrm{m}$ (NADW). These Ba* reversals are 


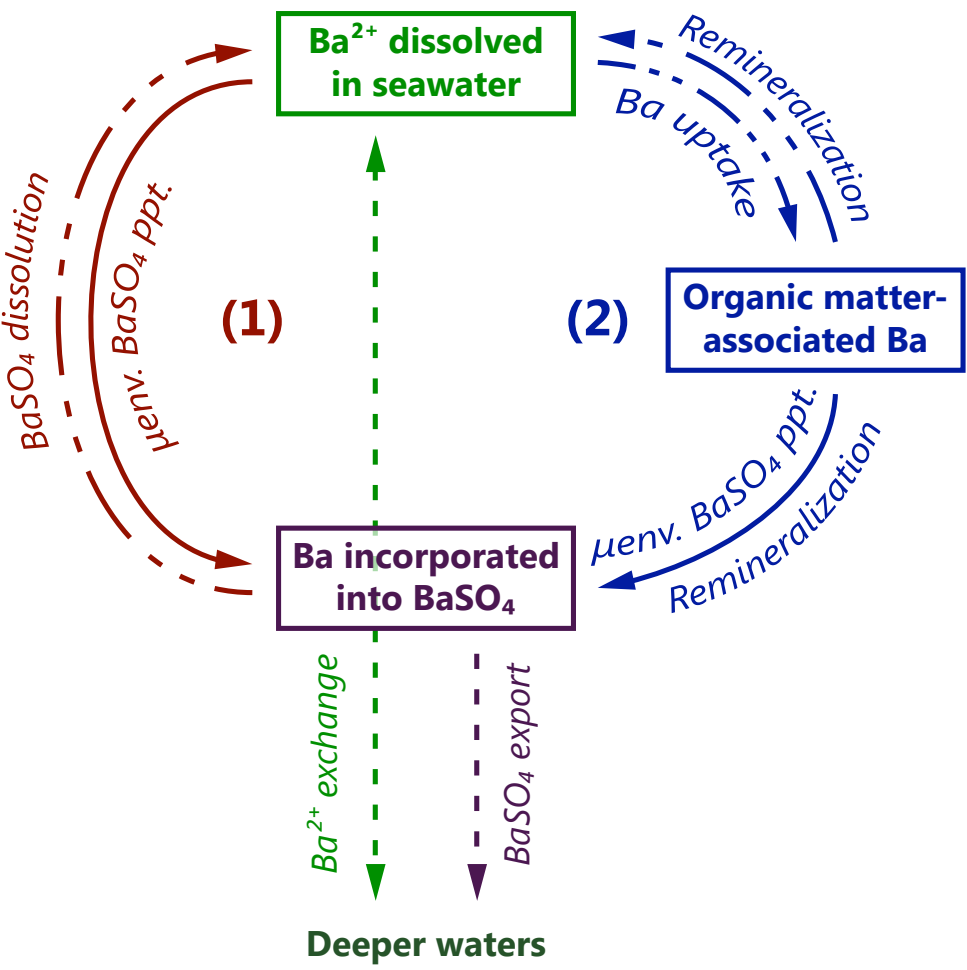

Figure 7: Conceptual model of upper water column cycling of Ba. Barium in $\mathrm{BaSO}_{4}$ is sourced from a continuum bracketed by (1) direct removal of dissolved $\mathrm{Ba}^{2+}$ from seawater or (2) removal through an intermediate, organic matter-associated pathway. In both pathways, $\mathrm{BaSO}_{4}$ precipitation is likely mediated by bacterial remineralization of POC in ephemeral microenvironments. Solid arrows indicate microenvironment-mediated $\mathrm{BaSO}_{4}$ precipitation, which results in a negative Ba-isotopic fractionation (e.g. Von Allmen et al., 2010); dotdashed arrows indicate processes whereby the sense of Ba-isotopic fractionation - if any - is unknown; dotted arrows indicate processes that are unlikely to significantly fractionate Ba-isotopic compositions. The export of organic matter-associated Ba into the ocean interior is not shown as this is likely a small fraction of the total inventory at St. 6. 
inconsistent with a vertical cycling process (see discussion below in Sec. 4.3). As such, the Ba* inflections in the deep ocean must reflect prior processing when at - or close to - the surface. This consideration alone suggests that $\mathrm{BaSO}_{4}$ cycling in the deep ocean is a relatively minor driver of deep dissolved [Ba] and $\delta^{138 / 134} \mathrm{Ba}_{\mathrm{NIST}}$ variations compared to near-surface cycling.

Within these large basin-scale preformed signatures there are also indications of more localized $\mathrm{BaSO}_{4}$ cycling processes. In particular, the relationship between $\delta^{138 / 134} \mathrm{Ba}_{\mathrm{NIST}}$ and $\mathrm{Ba}^{*}$ over the upper $600 \mathrm{~m}$ at St. 6 appears consistent with smaller, regional-scale $\mathrm{BaSO}_{4}$ cycling (Fig. 8b). Negative $\mathrm{Si}^{*}$ at $600 \mathrm{~m}$ indicates the influence of SAMW, which is an important source of nutrients to the thermocline at low latitudes (e.g. Sarmiento et al., 2004). The conservation of SAMW-like $\mathrm{Si}^{*}$ of $-10 \mu \mathrm{M}$ between $600 \mathrm{~m}$ and the surface further suggests that $\mathrm{Si}$ and $\mathrm{N}$ are (re)cycled stoichiometrically over this depth range. Given the importance of SAMW in supplying nutrients, and presumably Ba, to the thermocline at this locality, the subsurface maximum in Ba* associated with the core of SAMW/AAIW at $600 \mathrm{~m}$ (Figs. 6 and $8 \mathrm{a}$ ) is also likely to be influencing the starting Ba* of the thermocline at St. 6 . That there is a systematic decrease in $\mathrm{Ba}^{*}$ between $600 \mathrm{~m}$ and the surface - seen here at St. 6 (Fig. 8a) and at other stations in the low latitude South Atlantic (Fig. 6) - is suggestive of at least one additional process that is largely unique to modulating Ba distributions over this depth range.

The decrease in $\mathrm{Ba}^{*}$ of $\approx 7 \mathrm{nM}$ between $600 \mathrm{~m}$ and $200 \mathrm{~m}$ is associated with an increase in $\delta^{138 / 134} \mathrm{Ba}_{\mathrm{NIST}}$ of $\approx+0.1 \%$. These changes are consistent with near-surface waters having seen preferential removal of $\mathrm{Ba}$ relative to $\mathrm{Si}$. This depletion furthermore renders residual dissolved $\mathrm{Ba}$ in seawater isotopically heavy with respect to the Ba at the base of the thermocline (Fig. 8b). Importantly, this coupled decrease in $\mathrm{Ba}^{*}$ and increase in dissolved $\delta^{138 / 134} \mathrm{Ba}_{\mathrm{NIST}}$ occurs without significant modulation of $\mathrm{Si}^{*}$ (Fig. 8c), indicating a Ba cycling process that is decoupled from the algal macronutrients. The precipitation and dissolution of $\mathrm{BaSO}_{4}$ is an obvious candidate for such a process. If assuming that these changes are solely associated with $\mathrm{BaSO}_{4}$ cycling and not simply distinct preformed Ba signatures of different near-surface water masses, or resulting from Ba removal associated with organic matter, it is possible to estimate $\alpha_{\mathrm{BaSO}_{4}-\mathrm{SW}}$ : the Ba-isotopic fractionation factor associated with $\mathrm{BaSO}_{4}$ precipitation. Assuming steadystate fractionation, the best-fit York regression of $\delta^{138 / 134} \mathrm{Ba}_{\mathrm{NIST}}$ against [Ba] yields $\alpha_{\mathrm{BaSO}_{4}-\mathrm{SW}}=0.99972 \pm 0.00010$, equivalent to $\Delta_{\mathrm{BaSO}_{4}-\mathrm{SW}}=-0.28 \pm 0.10 \%$ o $\left( \pm 2 \mathrm{SD} ;\right.$ Fig. $\left.5 ; \alpha_{\mathrm{BaSO}_{4}-\mathrm{SW}}={ }^{138 / 134} \mathrm{Ba}_{\mathrm{BaSO}_{4}} /{ }^{138} / 134 \mathrm{Ba}_{\text {seawater }}\right)$.

Estimates of $\alpha_{\mathrm{BaSO}_{4}-\mathrm{SW}}$ using regression are crude approximations of oceanic processes taking place over large spatial scales. This is especially true since some of the decrease in [Ba] and increase in $\delta^{138 / 134} \mathrm{Ba}_{\mathrm{NIST}}$ from $600 \mathrm{~m}$ to $200 \mathrm{~m}$ is likely also associated with changes in preformed water mass signatures as well as $\mathrm{BaSO}_{4}$ precipitation. Indeed, we would predict a decrease in [Ba] between $600 \mathrm{~m}$ and $200 \mathrm{~m}$ of $\approx 5 \mathrm{nM}$ based on the decrease in dissolved [Si] of $\approx 11 \mu \mathrm{M}$ over the equivalent depth range (Figs. 1 and $3 \mathrm{~h}$ ). That the total decrease in [Ba] is larger $(\approx 14 \mathrm{nM})$ places an upper limit of $\leq 60 \%$ of the proportion of the near-surface Ba drawdown resulting from $\mathrm{BaSO}_{4}$ precipitation, with the remaining $\geq 40 \%$ resulting from mixing between water masses with different preformed [Ba] and $\delta^{138 / 134} \mathrm{Ba}_{\mathrm{NIST}}$. Since preformed $\delta^{138 / 134} \mathrm{Ba}_{\text {NIST }}$ is unknown, it is not possible to correct for preformed Ba in our regression to calculate a truer isotopic fractionation factor. As such, our estimate of $\alpha_{\mathrm{BaSO}_{4}-\mathrm{SW}}=0.99972 \pm 0.00010$ represents a minimum value for the Ba-isotopic fractionation factor associated with $\mathrm{BaSO}_{4}$ precipitation in seawater at St. 6. However, it is worth noting that the degree of $\mathrm{Ba}$ drawdown at $200 \mathrm{~m}$ relative to $600 \mathrm{~m}$ is very low $(\approx 25 \%)$; if the changes in the preformed [Ba] and $\delta^{138 / 134} \mathrm{Ba}_{\mathrm{NIST}}$ components over the same depth range were also set by $\mathrm{BaSO}_{4} \mathrm{cycling}$, the mixing line linking samples from $200-600 \mathrm{~m}$ - though hyperbolic - would plot essentially parallel to the modeled steady-state fractionation trend. This latter consideration may explain why our crude estimate of $\alpha_{\mathrm{BaSO}_{4}-\mathrm{SW}}$ matches the direction and is of a similar magnitude to the experimentally-determined $\alpha_{\mathrm{BaSO}_{4}-\mathrm{SW}}$ of $0.99968 \pm 0.00003$ for $\mathrm{BaSO}_{4}$ precipitation from solution at $21^{\circ} \mathrm{C}$ (Von Allmen et al., 2010).

The results of these analyses lead us to conclude that the signature of regional-scale $\mathrm{BaSO}_{4}$ cycling in the water column is most clearly imprinted on $\delta^{138 / 134} \mathrm{Ba}_{\mathrm{NIST}}$ between 600 and $200 \mathrm{~m}$ at St. 6. Though some $\mathrm{BaSO}_{4} \mathrm{may}$ be forming below $600 \mathrm{~m}$, the Ba-isotopic imprint of deep $\mathrm{BaSO}_{4}$ precipitation is not evident above the preformed water mass 'background' $\delta^{138 / 134} \mathrm{Ba}_{\mathrm{NIST}}$. Our inference that the greatest proportion of $\mathrm{BaSO}_{4}$ cycling occurs above $600 \mathrm{~m}$ is consistent with the depth ranges inferred from the analysis of peak Ba abundances in marine particulate matter (e.g. Bishop, 1988) and their frequent co-occurrence with the dissolved oxygen minimum associated with the locus of maximum POC remineralization (e.g. Dehairs et al., 1990). However, the depths at which these $\mathrm{BaSO}_{4}$ 

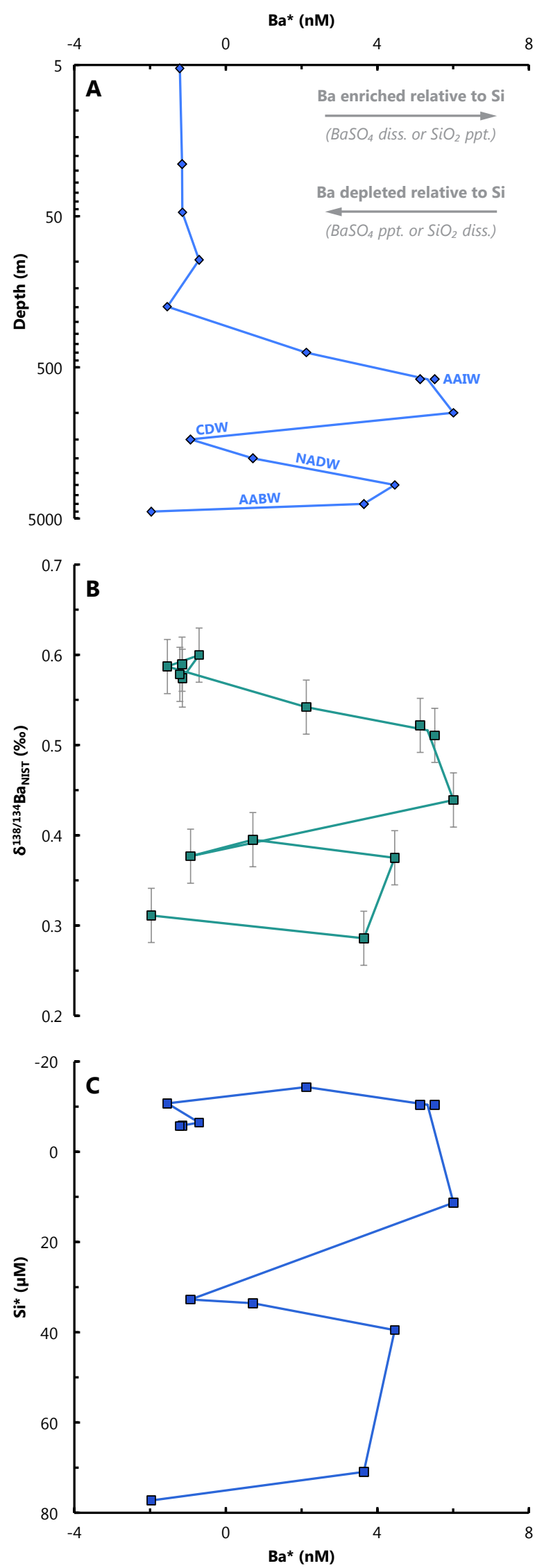

Figure 8: Interrelationships between Ba and Si at Station 6. A Depth profile of Ba* (defined in Eq. 2); note the logarithmic depth scale. Arrows indicate the predicted effects of $\mathrm{BaSO}_{4}$ and $\mathrm{SiO}_{2}$ precipitation and dissolution on $\mathrm{Ba}^{*}$. Crossplots showing $\mathbf{B} \delta^{138 / 134} \mathrm{Ba}_{\mathrm{NIST}}$ and $\mathbf{C}$ Si ${ }^{*}$ (defined in Fig. 3 caption; note reversed scale) against Ba*. 
cycling-associated Ba-isotopic signatures occur in the water column likely exhibit significant spatial variability. This variability will depend on both basin-scale circulation features and regional-scale $\mathrm{BaSO}_{4}$ formation processes. Additional, spatially-distributed profiles of dissolved [Ba], $\delta^{138 / 134} \mathrm{Ba}_{\mathrm{NIST}}$, and $\mathrm{Ba}^{*}$ - ideally coupled to analyses of marine particulates - will greatly assist in placing more quantitative constraints on the proportion of marine $\mathrm{BaSO}_{4}$ formed at different depths.

\subsection{The role of large-scale oceanic circulation and mixing}

We contend that regional circulation features exert a strong influence over dissolved $\delta^{138 / 134} \mathrm{Ba}_{\mathrm{NIST}}$ and, by inference, [Ba] in the South Atlantic Ocean. Of particular interest are origins of the large changes in $\mathrm{Ba}^{*}$ that occur in the deep ocean at St. 6, and whether they relate to vertical cycling processes or regional circulation features. Between $1,000-1,500 \mathrm{~m}$ and 4,000-4,500 m, Ba* decreases by $\approx 7$ and $6 \mathrm{nM}$, respectively. If the origin of these features were related strictly to vertical cycling - that is, precipitation and dissolution of $\mathrm{BaSO}_{4}$ in the deep ocean - dissolved [Ba] and $\delta^{138 / 134} \mathrm{Ba}_{\mathrm{NIST}}$ should also exhibit systematic decreases and increases, respectively (e.g. Sec. 4.2.2; Von Allmen et al., 2010). Between 1,000 - 1,500 m, [Ba] increases by $4.0 \mathrm{nM}$ and $\delta^{138 / 134} \mathrm{Ba}_{\mathrm{NIST}}$ decreases by $0.06 \pm 0.04 \%$ o (Fig. 4), which runs counter to our prior expectation of how $\mathrm{BaSO}_{4}$ precipitation should modulate Ba distributions at these depths. Below 4,000 m, [Ba] decreases by $2.0 \mathrm{nM}$, which is consistent with $\mathrm{BaSO}_{4}$ precipitation, though the observed increase in $\delta^{138 / 134} \mathrm{Ba}_{\mathrm{NIST}}$ of $+0.03 \pm 0.04 \%$ is not statistically significant. In both cases however, the decreases in $\mathrm{Ba}^{*}$ are also associated with increases in $\mathrm{Si}^{*}$ (Fig. 8c), with the latter reflecting basin-scale accumulated Si regeneration and differences in preformed $\mathrm{Si}^{*}$ between water masses. This, and the considerations from the previous sections lead us to conclude that the vertical cycling component driving $\mathrm{Ba}^{*}$ is small compared to preformed water mass signatures.

Further evidence of the importance of regional circulation is evident in the relationships between $\delta^{138 / 134} \mathrm{Ba}_{\mathrm{NIST}}, \mathrm{Si}^{*}$, and $1 /[\mathrm{Ba}]$ (Fig. 9). $\mathrm{Si}^{*}$ is only conserved in water masses where dissolved silicic acid and nitrate are recycled in a $1: 1$ ratio, and is strongly influenced by processes taking place in the Southern Ocean (Sarmiento et al., 2004). At St. 6, the depth profile of $\mathrm{Si}^{*}$ is dominated by distinct water mass signatures (Fig. 3i), with values $\approx-8 \mu \mathrm{M}$ between the surface and $600 \mathrm{~m}$, increasing to $\approx 35 \mu \mathrm{M}$ between $1,500-3,000 \mathrm{~m}$, and up to $\approx 74 \mu \mathrm{M}$ by $4,000-$ 4,500 m, corresponding to SAMW/AAIW, CDW/NADW, and AABW, respectively. Barium-isotopic compositions are strongly negatively correlated with those of $\mathrm{Si}^{*}$ for waters $\geq 600 \mathrm{~m}\left(R^{2}=0.97, n=8\right.$; Fig. 9a). However, seawater samples from above $600 \mathrm{~m}$ plot above the linear array seen in the deep ocean, with $\delta^{138 / 134} \mathrm{Ba}_{\mathrm{NIST}}$ increasing from $\approx+0.5$ at $600 \mathrm{~m}$ to $+0.6 \%$ at the surface (Fig. 9a). Ba* also decreases between 600 and the surface, whilst $\mathrm{Si}^{*}$ remains roughly constant between $\approx-14$ and $-6 \mu \mathrm{M}$ (Fig. 8c). Such interrelationships require a process that can systematically decrease [Ba] relative to [Si] - without substantially altering Si or N cycling - that furthermore renders residual Ba in seawater isotopically heavy; such interrelationships appear uniquely consistent with $\mathrm{BaSO}_{4} \mathrm{cycling}$.

In addition to constraints from $\mathrm{Si}^{*}$, we also compared $\delta^{138 / 134} \mathrm{Ba}_{\mathrm{NIST}}$ against $1 /$ [Ba] (Fig. 9b). Since Ba is the denominator on both axes, conservative mixing between two end-members should result in straight lines. Despite the profile encompassing at least four major water masses in the oceanic interior, the profile collapses into just two linear arrays: samples from $\geq 1,000 \mathrm{~m}$ and samples from $\leq 600 \mathrm{~m}$; the intersection between the two trends occurring at $\delta^{138 / 134} \mathrm{Ba}_{\text {NIST }}=+0.50 \%$ and $[\mathrm{Ba}]=63 \mathrm{nM}$ (Fig. $9 \mathrm{~b}$ ). Samples from $\leq 600 \mathrm{~m}$ correspond to the Si ${ }^{*}$-decoupled array in Fig. 9a, which likely reflects a contribution from near-surface $\mathrm{BaSO}_{4}$ cycling and mixing between water masses with distinct preformed [Ba] and $\delta^{138 / 134} \mathrm{Ba}_{\mathrm{NIST}}$. In the deep ocean $\geq 1,000 \mathrm{~m}$, the mixing of water masses with distinct $\left[\mathrm{Ba}\right.$ ] and $\delta^{138 / 134} \mathrm{Ba}_{\mathrm{NIST}}$ appears conservative within current analytical precision (Fig. 9b), providing further evidence of the importance of oceanic circulation in modulating deep ocean Ba distributions. Given the large spatial scales required to set these mixing relationships, it is reasonable to conclude that the correlation between [Ba] and [Si] in the deep South Atlantic Ocean is largely driven by oceanic circulation rather than processes specific to the vertical cycling of particulate Ba and Si carrier phases.

The arguments presented above suggests that preformed water mass signatures are largely responsible for the considerable Ba-isotopic variation seen in the deep South Atlantic (Fig. 4b). Two further, related questions arise from 

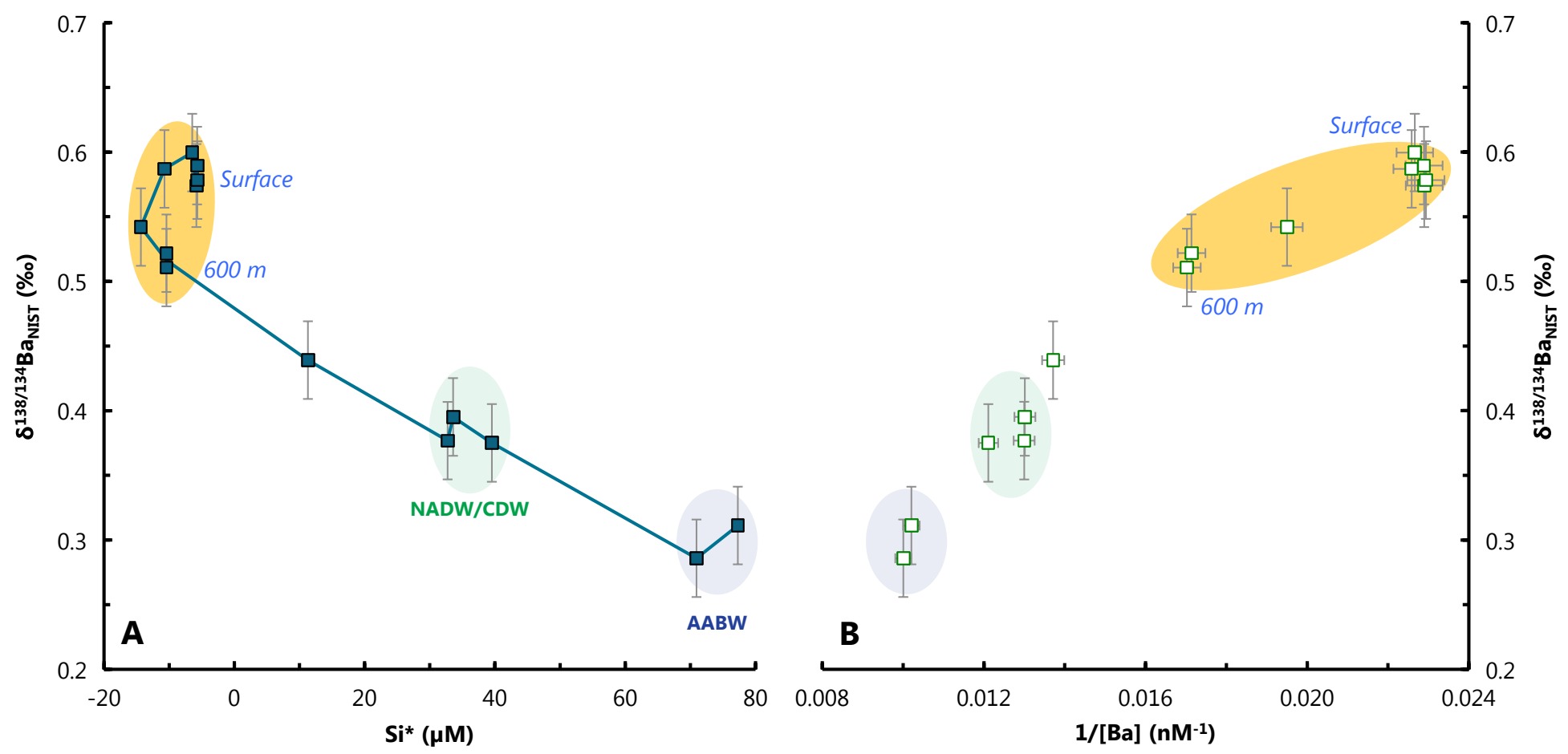

Figure 9: Barium-isotopic mixing relationships at St. 6. Shaded region highlights samples $\leq 600 \mathrm{~m}$. A $\delta^{138 / 134} \mathrm{Ba}_{\mathrm{NIST}}$ against $\mathrm{Si}^{*}$. The linear relationship between $\delta^{138 / 134} \mathrm{Ba}_{\text {NIST }}$ and $\mathrm{Si}^{*}$ in waters $\geq 600 \mathrm{~m}$ suggests that preformed Ba dominates the bathypelagic zone along $40{ }^{\circ} \mathrm{S}$. Barite cycling would cause samples to fall away from this linear relationship, which is most evident in samples collected above $600 \mathrm{~m}$. B $\delta^{138 / 134} \mathrm{Ba}$ against $1 /[\mathrm{Ba}$. In an isotopic ratio versus trace element plot, mixing relationships plot as straight lines if the denominator is the same on both axes (i.e. Ba).

this conclusion that are worth addressing given the potential for Ba-isotopic analyses to study POC remineralization in the modern and paleo-oceans. Firstly, why does $\delta^{138 / 134} \mathrm{Ba}_{\mathrm{NIST}}$ exhibit so much variation in the deep ocean compared to the isotopic compositions of other nutrient-type elements such as $\mathrm{Si}-, \mathrm{N}-$, or $\mathrm{Cd}$ ? Secondly, to what extent are these differences related to regionally-variable near-surface biogeochemical processes compared to circulation features?

One possible answer to the first question may relate to the recycling efficiency of particulate $\mathrm{BaSO}_{4}$ in the subsurface. Nitrate and cadmium are recycled very efficiently in the upper water column, resulting in largely homogeneous $\mathrm{N}$ - and Cd-isotopic compositions in the oceanic interior, albeit with some notable exceptions (e.g. Sigman et al., 2009; Xue et al., 2013). In contrast, near-surface Si recycling efficiency is spatially variable (e.g. Holzer et al., 2014), which likely contributes to the regional differences in the preformed Si-isotopic compositions of northern- versus southern-sourced deep water masses (e.g. de Souza et al., 2014). Thus, variations in dissolved N- and Cd-isotopic compositions are primarily related to water depth, whereas dissolved Si-isotopic compositions show systematic meridional and depth-dependent gradients. The overall similarity between marine [Ba] and [Si] distributions may indicate that $\mathrm{Ba}$ - is more akin to Si-isotopic distributions than $\mathrm{N}$ - or $\mathrm{Cd}$-isotopic distributions, potentially indicative of spatial variability in $\mathrm{BaSO}_{4}$ recycling efficiency. However, more co-located profiles of dissolved [Ba], $\mathrm{Ba}{ }^{*}$, and $\delta^{138 / 134} \mathrm{Ba}_{\mathrm{NIST}}$ - particularly from the subpolar regions where production of particulate $\mathrm{BaSO}_{4}$ is greatest (e.g. Bishop, 1989) - are clearly required to fully answer this question. Possible answers to the second question are even more speculative. At present, virtually nothing is known as to the relative importance of biological and chemical factors, such as the type or quantity of $\mathrm{POC}$ and dissolved $\mathrm{BaSO}_{4}$ saturation state (e.g. Monnin et al., 1999), respectively, in modulating Ba-isotopic fractionation in seawater, compared to the physical circulation of the ocean. Coordinated experimental, observational, and modeling efforts will be required to tease apart these processes, which will help elucidate the mechanistic linkages between the microbial oxidation of $\mathrm{POC}$, pelagic $\mathrm{BaSO}_{4}$ formation, Ba-isotopic fractionation in seawater, and the export of $\mathrm{BaSO}_{4}$ and organic carbon. 


\section{Conclusions}

We report the first full oceanographic depth profile of paired [Ba]- $\delta^{138 / 134} \mathrm{Ba}_{\mathrm{NIST}}$ from the South Atlantic Ocean using a double spike-multiple-collector inductively-coupled plasma mass spectrometry protocol. Our data show systematic and oceanographically-consistent variation with depth that exhibit subtle deviations from perfectly coupled [Ba]-[Si] behavior, which we quantify using a new tracer: $\mathrm{Ba}^{*}$. In property-property space, the relationship between Ba-isotopic compositions and $\mathrm{Ba}^{*}$ suggests that Ba-isotopic variations originate when water masses are at or near the surface. Mass balance considerations strongly suggest that most of these variations are associated with the cycling of particulate $\mathrm{BaSO}_{4}$ and not organic carbon, though the formation of $\mathrm{BaSO}_{4}$ is itself likely mediated by microbial activity associated with the remineralization of organic matter. Precipitation of $\mathrm{BaSO}_{4}$ renders Ba-depleted seawater with heavier Ba-isotopic compositions; the minimum associated isotopic fractionation factor is estimated as $\alpha_{\mathrm{BaSO}_{4}-\mathrm{SW}}=0.99972 \pm 0.00010$, which is consistent with the direction and magnitude of an experimental study. Barium-isotopic variations in the deep ocean are clearly influenced by large-scale oceanic circulation. Indeed, the deep ocean variation is well explained by conservative mixing between the major South Atlantic water masses that each possess distinct $\left[\mathrm{Ba}\right.$ ] and $\delta^{138 / 134} \mathrm{Ba}_{\mathrm{NIST}}$. Large-scale oceanic circulation may thus help to sustain the linear [Ba]-[Si] correlation in the South Atlantic, and possibly elsewhere. More broadly, our data attest to the important linkages between the remineralization of organic carbon, $\mathrm{BaSO}_{4}$ precipitation, and Ba-isotopic fractionation in seawater. Though many of the mechanistic links remain to be fully elucidated, the patterns seen here in the South Atlantic are extremely promising for the development of Ba-isotopic analyses as a tracer of the marine carbon cycle, past and present.

\section{Acknowledgments}

We thank G.M. Henderson and all who participated in GA10E/D357 for sharing samples from UK-GEOTRACES $40^{\circ}$ S; J.S. Blusztajn and G. Swarr for keeping the WHOI Plasma Mass Spectrometry Facility shipshape; S.N. Burgess for manufacturing the Ba-isotopic double spike; A. Vilela, J.M. Godoy, F. Dehairs, T. Roeske, and M. Rutgers v. d. Loeff for sharing [Ba] data for use in Fig. 1; C.G. Richards for processing St. 6 CTD data; and K.R. Hendry, A. Paytan, and P.J. Lam for discussions. Detailed and thoughtful reviews by an anonymous reviewer and G.F. de Souza greatly improved the manuscript, as did editorial comments from M. Frank. T.J.H. acknowledges support from Makoto A. Saito (Gordon and Betty Moore Foundation; Project \# 3782) and the Postdoctoral Scholar Program at the Woods Hole Oceanographic Institution, with funding provided by the Doherty Foundation. Development of Ba-isotopic

protocols at NIRVANA was made possible with funding from The Andrew W. Mellon Foundation Endowed Fund for Innovative Research (T.J.H. and S.G.N.). 


\section{References}

Bertram, M.A., Cowen, J.P., 1997. Morphological and compositional evidence for biotic precipitation of marine barite. J. Mar. Res. 55, 577-593. doi:10.1357/0022240973224292.

Bishop, J.K.B., 1988. The barite-opal-organic carbon association in oceanic particulate matter. Nature 332, 341-343. doi:10.1038/332341a0.

Bishop, J.K.B., 1989. Regional Extremes in Particulate Matter Composition and Flux: Effects on the Chemistry of the Ocean Interior, in: Berger, W.H., Smetacek, V.S., Wefer, G. (Eds.), Productivity of the Ocean: Present and Past. Wiley. volume 54 of Dahlem Workshop Reports, pp. 117-137.

Bishop, J.K.B., Wood, T.J., 2008. Particulate matter chemistry and dynamics in the twilight zone at VERTIGO ALOHA and K2 sites. Deep Sea Res. Part I 55, 1684-1706. doi:10.1016/j.dsr .2008.07.012.

Böttcher, M.E., Geprägs, P., Neubert, N., Von Allmen, K., Pretet, C., Samankassou, E., Nägler, T.F., 2012. Barium isotope fractionation during experimental formation of the double carbonate $\mathrm{BaMn}\left(\mathrm{CO}_{3}\right)_{2}$ at ambient temperature. Isot. Environ. Health Stud. 48, 457-463. doi:10.1080/10256016.2012.673489.

Broecker, W.S., Peng, T.H., 1982. Tracers in the Sea. Lamont-Doherty Geological Observatory, Columbia University.

Chan, L.H., Drummond, D., Edmond, J.M., Grant, B., 1977. On the barium data from the Atlantic GEOSECS expedition. Deep Sea Res. 24, 613-649. doi:10.1016/0146-6291(77)90505-7.

Chow, T.J., Goldberg, E.D., 1960. On the marine geochemistry of barium. Geochim. Cosmochim. Acta 20, $192-198$. doi:10.1016/0016-7037(60)90073-9.

Dehairs, F., Chesselet, R., Jedwab, J., 1980. Discrete suspended particles of barite and the barium cycle in the open ocean. Earth Planet. Sci. Lett. 49, 528-550. doi:10.1016/0012-821X (80)90094-1.

Dehairs, F., Goeyens, L., Stroobants, N., Bernard, P., Goyet, C., Poisson, A., Chesselet, R., 1990. On suspended barite and the oxygen minimum in the Southern Ocean. Global Biogeochem. Cycles 4, 85-102. doi:10.1029/ GB004i001p00085.

Dehairs, F., Jacquet, S., Savoye, N., Van Mooy, B.A., Buesseler, K.O., Bishop, J.K., Lamborg, C.H., Elskens, M., Baeyens, W., Boyd, P.W., Casciotti, K.L., Monnin, C., 2008. Barium in twilight zone suspended matter as a potential proxy for particulate organic carbon remineralization: Results for the North Pacific. Deep Sea Res. Part II 55, 1673-1683. doi:10.1016/j.dsr2.2008.04.020.

Dideriksen, K., Baker, J.A., Stipp, S.L.S., 2006. Iron isotopes in natural carbonate minerals determined by MC-ICP-MS with a ${ }^{58} \mathrm{Fe}-{ }^{54} \mathrm{Fe}$ double spike. Geochim. Cosmochim. Acta 70, 118-132. doi:10.1016/j .gca. 2005.08.019.

Dymond, J., Suess, E., Lyle, M., 1992. Barium in deep-sea sediment: A geochemical proxy for paleoproductivity. Paleoceanography 7, 163-181. doi:10.1029/92PA00181.

Eagle, M., Paytan, A., Arrigo, K.R., van Dijken, G., Murray, R.W., 2003. A comparison between excess barium and barite as indicators of carbon export. Paleoceanography 18. doi:10.1029/2002PA000793.

Esser, B.K., Volpe, A.M., 2002. At-sea high-resolution chemical mapping: extreme barium depletion in North Pacific surface water. Mar. Chem. 79, 67-79. doi:10.1016/S0304-4203(02)00037-3.

Falkner, K.K., MacDonald, R.W., Carmack, E.C., Weingartner, T., 1994. The potential of barium as a tracer of Arctic water masses, in: Johannessen, O.M., Muench, R.D., Overland, J.E. (Eds.), The Polar Oceans and Their Role in Shaping the Global Environment. American Geophysical Union. volume 85 of Geophys. Monogr., pp. 63-76. doi:10 . 1029/GM085p0063.

Foster, D.A., Staubwasser, M., Henderson, G.M., 2004. ${ }^{226}$ Ra and Ba concentrations in the Ross Sea measured with multicollector ICP mass spectrometry. Mar. Chem. 87, 59-71. doi:10.1016/j . marchem. 2004.02.003. 
Ganeshram, R.S., François, R., Commeau, J., Brown-Leger, S.L., 2003. An experimental investigation of barite formation in seawater. Geochim. Cosmochim. Acta 67, 2599-2605. doi:10.1016/S0016-7037 (03)00164-9.

González-Muñoz, M.T., Martinez-Ruiz, F., Morcillo, F., Martin-Ramos, J.D., Paytan, A., 2012. Precipitation of barite by marine bacteria: A possible mechanism for marine barite formation. Geology 40, 675-678. doi:10.1130/ G33006.1.

González-Muñoz, M. T., M.T., Fernández-Luque, B., Martínez-Ruiz, F., Chekroun, K.B., Arias, J.M., RodríguezGallego, M., Martínez-Canamero, M., De Linares, C., Paytan, A., 2003. Precipitation of Barite by Myxococcus xanthus: Possible Implications for the Biogeochemical Cycle of Barium. Appl. Environ. Microbiol. 69, 5722-5725. doi:10.1128/AEM.69.9.5722-5725.2003.

Griffith, E.M., Paytan, A., 2012. Barite in the ocean-occurrence, geochemistry and palaeoceanographic applications. Sedimentology 59,1817-1835. doi:10.1111/j.1365-3091.2012.01327.x.

Gruber, N., Sarmiento, J.L., 1997. Global patterns of marine nitrogen fixation and denitrification. Global Biogeochem. Cycles 11, 235-266. doi:10.1029/97GB00077.

Herndl, G.J., Reinthaler, T., 2013. Microbial control of the dark end of the biological pump. Nat. Geosci. 6, 718-724. doi:10.1038/ngeo1921.

Hofmann, A.E., Bourg, I.C., DePaolo, D.J., 2012. Ion desolvation as a mechanism for kinetic isotope fractionation in aqueous systems. Proc. Natl. Acad. Sci. 109, 18689-18694. doi:10.1073/pnas. 1208184109.

Holzer, M., Primeau, F.W., DeVries, T., Matear, R., 2014. The Southern Ocean silicon trap: Data-constrained estimates of regenerated silicic acid, trapping efficiencies, and global transport paths. J. Geophys. Res. Oceans 119, 313-331. doi:10.1002/2013JC009356.

Hoppema, M., Dehairs, F., Navez, J., Monnin, C., Jeandel, C., Fahrbach, E., De Baar, H.J.W., 2010. Distribution of barium in the Weddell Gyre: Impact of circulation and biogeochemical processes. Mar. Chem. 122, 118-129. doi:10.1016/j.marchem.2010.07.005.

Jacquet, S.H.M., Dehairs, F., Cardinal, D., Navez, J., Delille, B., 2005. Barium distribution across the southern ocean frontal system in the crozet-kerguelen basin. Mar. Chem. 95, 149-162. doi:10.1016/j .marchem.2004.09.002.

Ma, Z., Gray, E., Thomas, E., Murphy, B., Zachos, J., Paytan, A., 2014. Carbon sequestration during the PalaeoceneEocene Thermal Maximum by an efficient biological pump. Nat. Geosci. 7, 382-388. doi:10.1038/ngeo2139.

Mawji, E., et al., 2015. The GEOTRACES Intermediate Data Product 2014. Mar. Chem. , 8doi:10.1016/j .marchem . 2015.04 .005$.

Miyazaki, T., Kimura, J.I., Chang, Q., 2014. Analysis of stable isotope ratios of Ba by double-spike standard-sample bracketing using multiple-collector inductively coupled plasma mass spectrometry. J. Anal. At. Spectrom. 29, 483-490. doi:10.1039/c3ja50311a.

Monnin, C., Jeandel, C., Cattaldo, T., Dehairs, F., 1999. The marine barite saturation state of the world's oceans. Mar. Chem. 65, 253-261. doi:10.1016/S0304-4203(99)00016-X.

Paytan, A., Griffith, E.M., 2007. Marine barite: Recorder of variations in ocean export productivity. Deep Sea Res. Part II 54,687-705. doi:10.1016/j.dsr2 .2007.01.007.

Pretet, C., 2014. Non-Traditional Isotopes (Barium and Calcium) and Elemental Ratios in Scleractinian Coral Skeleton: New Look into Geochemical Cycles, Environmental Proxies and Bio-Calcification Processes. Ph.D. thesis. University of Geneva. URL: http://archive-ouverte.unige.ch/unige:33163.

Roeske, T., Bauch, D., Rutgers v. d. Loeff, M., Rabe, B., 2012a. Utility of dissolved barium in distinguishing North American from Eurasian runoff in the Arctic Ocean. Mar. Chem. 132, 1-14. doi:10.1016/j .marchem. 2012.01.007. 
Roeske, T., Rutgers v. d. Loeff, M., 2012. Barium measured on water bottle samples during POLARSTERN cruise ANT-XXIV/3. doi:10.1594/PANGAEA.786619.

Roeske, T., Loeff, M., Middag, R., Bakker, K., 2012b. Deep water circulation and composition in the Arctic Ocean by dissolved barium, aluminium and silicate. Mar. Chem. 132, 56-67. doi:10.1016/j.marchem. 2012.02.001.

Sarmiento, J., Simeon, J., Gnanadesikan, A., Gruber, N., Key, R., Schlitzer, R., 2007. Deep ocean biogeochemistry of silicic acid and nitrate. Global Biogeochem. Cycles 21. doi:10.1029/2006GB002720.

Sarmiento, J.L., Gruber, N., Brzezinski, M.A., Dunne, J.P., 2004. High-latitude controls of thermocline nutrients and low latitude biological productivity. Nature 427, 56-60. doi:10.1038/nature02127.

Schmitz, B., 1987. Barium, equatorial high productivity, and the northward wandering of the Indian continent. Paleoceanography 2, 63-77. doi:10.1029/PA002i001p00063.

Sigman, D.M., Altabet, M.A., McCorkle, D.C., François, R., Fischer, G., 1999. The $\delta^{15} \mathrm{~N}$ of nitrate in the Southern Ocean: Consumption of nitrate in surface waters. Global Biogeochem. Cycles 13, 1149-1166. doi:10.1029/ 1999GB900038.

Sigman, D.M., DiFiore, P.J., Hain, M.P., Deutsch, C., Wang, Y., Karl, D.M., Knapp, A.N., Lehmann, M.F., Pantoja, S., 2009. The dual isotopes of deep nitrate as a constraint on the cycle and budget of oceanic fixed nitrogen. Deep Sea Res. Part I 56, 1419-1439. doi:10.1016/j.dsr.2009.04.007.

de Souza, G.F., Reynolds, B.C., Rickli, J., Frank, M., Saito, M.A., Gerringa, L.J.A., Bourdon, B., 2012. Southern Ocean control of silicon stable isotope distribution in the deep Atlantic Ocean. Global Biogeochem. Cycles 26. doi:10.1029/2011GB004141.

de Souza, G.F., Slater, R.D., Dunne, J.P., Sarmiento, J.L., 2014. Deconvolving the controls on the deep ocean's silicon stable isotope distribution. Earth Planet. Sci. Lett. 398, 66-76. doi:10.1016/j .eps1.2014.04.040.

Speich, S., Sicre, M.A., Dehairs, F., 2008. BONUS-GoodHope Log \& Basic Files. URL: http://www.obs-vlfr.fr/ proof/bonusgh/.

Sternberg, E., Tang, D., Ho, T.Y., Jeandel, C., Morel, F.M.M., 2005. Barium uptake and adsorption in diatoms. Geochim. Cosmochim. Acta 69, 2745-2752. doi:10.1016/j.gca.2004.11.026.

Stroobants, N., Dehairs, F., Goeyens, L., Vanderheijden, N., Van Grieken, R., 1991. Barite formation in the Southern Ocean water column. Mar. Chem. 35, 411-421. doi:10.1016/S0304-4203(09)90033-0.

Van Beek, P., François, R., Conte, M., Reyss, J.L., Souhaut, M., Charette, M., 2007. ${ }^{228} \mathrm{Ra} /{ }^{226} \mathrm{Ra}$ and ${ }^{226} \mathrm{Ra} / \mathrm{Ba}$ ratios to track barite formation and transport in the water column. Geochim. Cosmochim. Acta 71, 71-86. doi:10.1016/j . gca.2006.07.041.

Von Allmen, K., Böttcher, M.E., Samankassou, E., Nägler, T.F., 2010. Barium isotope fractionation in the global barium cycle: First evidence from barium minerals and precipitation experiments. Chem. Geol. 277, 70-77. doi:10.1016/ j.chemgeo.2010.07.011.

Wolgemuth, K., Broecker, W.S., 1970. Barium in sea water. Earth Planet. Sci. Lett. 8, 372-378. doi:10.1016/ 0012-821X (70)90110-X.

Xue, Z., Rehkämper, M., Horner, T.J., Abouchami, W., Middag, R., van de Flierdt, T., de Baar, H.J.W., 2013. Cadmium isotope variations in the Southern Ocean. Earth Planet. Sci. Lett. 382, 161-172. doi:10.1016/j .eps1.2013.09.014. 